\title{
Misregulation of PPAR Functioning and Its Pathogenic Consequences Associated with Nonalcoholic Fatty Liver Disease in Human Obesity
}

\author{
Luis A. Videla ${ }^{1}$ and Paulina Pettinelli ${ }^{2}$ \\ ${ }^{1}$ Molecular and Clinical Pharmacology Program, Institute of Biomedical Sciences, Faculty of Medicine, University of Chile, \\ Casilla 70000, Santiago 7, Chile \\ ${ }^{2}$ Ciencias de la Salud, Nutrición y Dietética, Facultad de Medicina, Pontificia Universidad Católica de Chile, \\ 7820436 Santiago, Chile
}

Correspondence should be addressed to Luis A. Videla, lvidela@med.uchile.cl

Received 17 July 2012; Accepted 6 November 2012

Academic Editor: Keigo Machida

Copyright (C) 2012 L. A. Videla and P. Pettinelli. This is an open access article distributed under the Creative Commons Attribution License, which permits unrestricted use, distribution, and reproduction in any medium, provided the original work is properly cited.

Nonalcoholic fatty liver disease in human obesity is characterized by the multifactorial nature of the underlying pathogenic mechanisms, which include misregulation of PPARs signaling. Liver PPAR- $\alpha$ downregulation with parallel PPAR- $\gamma$ and SREBP1c up-regulation may trigger major metabolic disturbances between de novo lipogenesis and fatty acid oxidation favouring the former, in association with the onset of steatosis in obesity-induced oxidative stress and related long-chain polyunsaturated fatty acid n-3 (LCPUFA n-3) depletion, insulin resistance, hypoadiponectinemia, and endoplasmic reticulum stress. Considering that antisteatotic strategies targeting PPAR- $\alpha$ revealed that fibrates have poor effectiveness, thiazolidinediones have weight gain limitations, and dual PPAR- $\alpha / \gamma$ agonists have safety concerns, supplementation with LCPUFA n-3 appears as a promising alternative, which achieves both significant reduction in liver steatosis scores and a positive anti-inflammatory outcome. This latter aspect is of importance as PPAR- $\alpha$ downregulation associated with LCPUFA n-3 depletion may play a role in increasing the DNA binding capacity of proinflammatory factors, NF- $\kappa \mathrm{B}$ and AP- 1 , thus constituting one of the major mechanisms for the progression of steatosis to steatohepatitis.

\section{Introduction}

1.1. Epidemiologic Aspects. Nonalcoholic fatty liver disease (NAFLD) is considered the hepatic manifestation of metabolic syndrome (MetS) and has emerged as the most frequent cause of chronic liver disease worldwide, becoming the third most common indication for liver transplantation in order to rescue patients with end-stage liver disease $[1,2]$. NAFLD encompasses a wide disease spectrum ranging from simple triacylglycerol (TAG) accumulation in hepatocytes (hepatic steatosis), which is defined by accumulation of liver fat ( $>5 \%$ per liver weight) in the presence of $<20 \mathrm{~g}$ of daily alcohol consumption, to steatosis with inflammation (nonalcoholic steatohepatitis, NASH), fibrosis, and cirrhosis $[2,3]$. Liver biopsy is the gold standard for diagnosis and has the additional benefit of distinguishing between NASH and simple steatosis, thus allowing for the staging of the degree of fibrosis [4]. NAFLD affects 17 to $33 \%$ in the general populations, whereas that of NASH affects $2 \%$ to $3 \%$ of the population $[2,5]$. In obese subjects, NAFLD incidence reaches $60 \%$ to $90 \%$ and for NASH and hepatic cirrhosis $20 \%$ to $25 \%$ and $2 \%$ to $8 \%$, respectively. In subjects with MetS, the prevalence of NAFLD is increased fourfold compared with those without the disease, and 30\% of NAFLD subjects have MetS $[6,7]$. In children population, an autopsy study found that $9.6 \%$ of the American population aged 2 to 19 years has NAFLD, and this figure increased to $38 \%$ among those who were obese [8].

Obesity is a state of chronic low-grade inflammation accompanied by excess fat storage deposited in tissues other than adipose tissue, including liver and skeletal muscle, which may lead to local insulin resistance (IR) and may 
stimulate inflammation, as in NASH [9]. Therefore, obesity and IR, both key features of the MetS, are intimately linked and strongly associated with NAFLD progression $[3,10]$.

1.2. Etiopathology of NAFLD. The primary metabolic abnormalities that lead to hepatic steatosis involve a lipotoxic response with an oxidative-stress component, nutritional factors, and alterations in the lipid metabolism of the liver, which result from the development of IR [3]. Hepatic fat accumulation, secondary to IR, develops when there is an imbalance in which fatty acid uptake and de novo synthesis exceed oxidation and secretion [11]. In this respect, the sources that contribute to fatty liver are (i) delivery of dietary fat to the liver (contribution to liver fat $\sim 5 \%$ ); (ii) delivery of extrahepatic nonesterified fatty acids (NEFAs) to the liver (contribution to liver fat $\sim 60 \%$ ); (iii) the remainder of liver fat accumulation is related to hepatic de novo lipogenesis, which is increased in obese patients [12].

The retention of FAs and TAGs within the hepatocytes that depends on IR and hyperinsulinemia leads to the production of free radicals at a mitochondrial level, capable of inducing lipid peroxidation, cytokine production, and hepatocyte necrosis [13], which may trigger NAFLD progression to the more severe state of NASH $[2,3]$.

The regulation of hepatic lipogenesis and FA oxidation is under rigorous control that involves a complex network of nuclear receptors, which regulate the expression of enzymes that participate in the lipid metabolism in a coordinated manner [11].

1.3. PPARs. The ligand-activated transcription factors belonging to the peroxisome proliferators-activated receptors (PPARs) are a subfamily of the steroid/thyroid/retinoid receptors superfamily. PPARs act as fatty acid sensors to control many metabolic programs that are essential for systematic energy homeostasis, including adipocyte differentiation, inflammation and energy homeostasis, lipoprotein metabolism, and FA oxidation, representing an important target for NAFLD $[9,14,15]$. The PPAR family consists of three members, namely, PPAR $\alpha$ (NR1C1 according to the unified nomenclature system for the nuclear receptor superfamily), $\mathrm{PPAR} \beta / \delta$ (NR1C2), and PPAR $\gamma$ (NR1C3), with two forms, $\gamma 1$ and $\gamma 2$, with differing amino termini, each encoded by different genes [14]. Similar to most members of the superfamily, all PPAR isoforms have a highly conserved structure. They are composed of five different domains, (i) an aminoterminal A/B domain involved in ligand-independent transactivation, which in other cases can regulate DNA binding, (ii) a two zinc-finger DNA-binding domain (DBD) responsible for half-site specificity of target gene recognition, (iii) a hinge region, (iv) a carboxy-terminal ligand-binding domain (LBD) with $60 \sim 70 \%$ homology between the subtypes, and (v) a transactivation domain, called AF2 (activation function 2) [16-18]. To control gene expression, PPARs heterodimerize with 9-cisRXR, which bind to peroxisome proliferator response elements (PPRE) located in the promoters of their targets genes. The canonical PPRE consists of two direct repeats AGGTCA separated by a single nucleotide so-called DR-1 element [14]. Activation of target gene transcription depends on the binding of the ligand to the receptor. Ligand binding induces a conformational change in the LBD of the receptor that facilitates recruitment of coactivator molecules. Unliganded nuclear receptors recruit corepressors N-CoR and SMRT. For PPAR:RXR heterodimer, binding of the ligand of either receptor can activate the complex, but binding of both ligands simultaneously is more potent $[17,19]$. In this context, several studies have identified a series of endogenous and synthetic ligands for PPARs such as unsaturated fatty acids, oxidized low-density lipoproteins (LDL-ox), VLDL, metabolites derived from linoleic acid, fibrates, and thiazolidinediones $[14,20]$.

1.4. PPAR- $\alpha$. Liver plays a pivotal role in lipid metabolism by upregulating the expression of numerous genes involved in FA uptake through membranes, FA activation, intracellular FA trafficking, FA oxidation, and ketogenesis, in addition to TAG storage and lipolysis. Furthermore, PPAR- $\alpha$ also governs the metabolism of glucose, lipoprotein, and amino acids besides inflammatory processes, mainly by downregulating gene expression via a transrepression mechanism $[9,21]$ (for a detailed review see [21]). PPAR- $\alpha$ is well expressed in metabolically active tissues including liver, heart, kidney, intestine, macrophages, and brown adipose tissue, and it has mostly been studied in the context of liver parenchymal cells, where it is highly expressed [21]. Although the functionality of PPAR- $\alpha$ was initially questioned due it lower expression compared with mouse liver [22], a recent study showed that in liver tissue and primary hepatocytes, PPAR- $\alpha$ expression levels in mice are similar to humans [23]. However, in this context, it has to be considered the presence of both a truncated splice variant of human PPAR- $\alpha$ that negatively interferes with wild-type PPAR- $\alpha$ activity [24] and polymorphic variants in the functional coding sequence of human PPAR- $\alpha$, val227ala, and Leu162Val, which are implicated in NAFLD and IR but not with liver damage, respectively $[25,26]$. Natural ligands of PPAR- $\alpha$ include a variety of FAs as well as numerous FA derivatives and compounds showing structural resemblance to FAs, including acyl-CoAs, oxidized FAs, eicosanoids, endocannabinoids, and phytanic acid [27-29]. Synthetic PPAR- $\alpha$ ligands include fibrates such as gemfibrozil, bezafibrate, clofibrate, fenofibrate, and Wy14643, drugs that are used in the treatment of dyslipidemia primarily associated with type 2 diabetes mellitus [21].

1.5. PPAR- $\gamma$. PPAR- $\gamma$ is the master regulator in the control of genes involved in lipogenic pathways of adipocytes, promoting the uptake of FAs and the differentiation of the adipocyte, with the consequent increase in the cellular content of TAGs and reduction in the FA delivery to the liver [17]. Target genes of PPAR- $\gamma$ are involved in adipocyte differentiation, lipid storage, and glucose metabolism and include lipoprotein lipase, CD36, adipocyte FA binding protein aP2, FA transport protein, acyl-coA synthetase, phosphoenolpyruvate carboxykinase, aquaporin 7 , and citrate carrier $[9,30$, 31]. PPAR- $\gamma$ also confers sensitization to insulin through 
the transcriptional activation of the adiponectin gene in adipocytes, up-regulating its expression [32]. Ligands for PPAR- $\gamma$ include specific polyunsaturated fatty acid (PUFA) metabolites, several eicosanoids, and synthetic compounds with very high (nanomolar) affinity such as thiazolidinediones [17, 29].

Increased PPAR- $\gamma$ expression is a feature of the steatotic liver and several studies attribute a causal role of PPAR- $\gamma$ in steatosis development by mechanisms involving activation of lipogenic genes and de novo lipogenesis [33]. In humans, PPAR- $\gamma$ is much more abundant in adipose cells; yet reasonable levels of PPAR- $\gamma$ mRNA can also be found in other organs including skeletal muscle, colon, lung, and placenta. In contrast to adipose tissue, liver and heart express very little PPAR- $\gamma$; however, under certain pathological conditions, these tissues can express considerable amounts of PPAR- $\gamma$ that have significant impacts on metabolic homeostasis and tissue function [34].

Studies addressing the expression of PPAR- $\gamma$ in obese subjects revealed an increased adipose tissue expression of the splice variants PPAR- $\gamma 1$ and PPAR- $\gamma 2$, compared with lean subjects, suggesting that under pathological conditions and different nutritional situations, regulation of the human PPAR- $\gamma$ expression may change [35]. In some infectious diseases such as hepatitis B and C viruses, multiple observations suggest that liver steatosis is a common histological characteristic, in which an increase in the expression and/or activity of PPAR- $y$ could contribute to the regulation of lipid synthesis [36-38]. Furthermore, similar to PPAR- $\alpha$, it has to be considered PPAR- $\gamma$ variants, considering that Pro12Ala and C1431T polymorphisms alter the susceptibility to hepatic steatosis, lobular inflammation, and fibrosis in humans with NAFLD. It was suggested that subjects with a haplotype containing both minor Pro12Ala and C1431T alleles are at reduced risk for NAFLD, and its histological features are associated with NASH [39]. Similar results have been found in Chinese population [40], which is in agreement with previous results associating Pro12Ala variant with increased insulin sensitivity, lower body mass and protection from type 2 diabetes [41-43].

1.6. PPAR- $\delta$. Due to its ubiquitous expression profile, much less is known about PPAR- $\delta$ compared to PPAR- $\alpha$ and PPAR- $\gamma$ in relation to human obesity and NAFLD. Studies from a decade ago showed that insulin-resistant obese rhesus monkeys normalized fasting glucose and insulin, increased high-density lipoprotein-cholesterol, and reduced low-density lipoprotein cholesterol after treatment with the potent and specific PPAR- $\delta$ agonist GW501516, which is approximately 1200 times more selective for PPAR- $\delta$ than the $\alpha$ and $\gamma$ receptors [44]. Studies in an animal model of adenovirus-mediated hepatic PPAR- $\delta$ overexpression showed that PPAR- $\delta$ regulates lipogenesis and glucose utilization for glycogen synthesis. These effects could result in hepatic protection from free FA-mediated damage, possibly due to the generation of protective mono-unsaturated FA and lowering lipotoxic saturated FA levels [45]. Overweight and obese men subjected to PPAR- $\delta$ agonists GW501516 or
MBX-8025 improved insulin sensitivity and decreased fasting plasma TAGs, NEFAs, apoB-100, and LDL-cholesterol concentrations, with diminished liver fat content quantified by magnetic resonance imaging (MRI) [46-49]. Furthermore, recent studies showed that enhanced inflammation in visceral adipose tissue (VAT) is accompanied by a reduction in SIRT1 protein levels and PPAR- $\delta$ activity, in association with NF- $\kappa \mathrm{B}$ activation, in morbidly obese IR patients compared with normal and overweight subjects, suggesting interplay between PPAR- $\delta$ and NF- $\kappa$ B [50]. However, this contention and the mechanisms underlying PPAR- $\delta$ effects remain to be studied in the liver of obese patients.

Collectively, discussed data point to various molecular mechanisms underlying NAFLD, some of which are modulated by PPARs. The aim of this work is to review the alterations of PPAR functioning and its pathogenic consequences associated with NAFLD in human obesity.

\section{The Role of PPAR- $\alpha$ Downregulation in Liver Steatosis}

Simple TAG accumulation in hepatocytes or steatosis is an early hallmark in NAFLD associated with obesity that is characterized by the multifactorial nature of the underlying pathogenic mechanisms, including the development of oxidative stress and insulin resistance $[3,52,53]$, which provides the setting for further hepatic injury [54]. In this respect, the concept of nutritional or dietary oxidative stress has been introduced to denote an imbalance between the prooxidant load and the antioxidant defence, resulting from excess oxidative load or inadequate supply of the organism with nutrients [55]. Prolonged consumption of calorieenriched diets stimulates fatty acid (FA) synthesis from glucose, and FAs in excess are converted into TAGs and store as lipid droplets within hepatocytes (Figure 1) [56]. FA overloading in the liver may favour high rates of FA oxidation due to substrate pressure, with consequent reactive oxygen species (ROS) generation [3]. This contention is supported by studies in J774.2 macrophages, which upon TAG overload generate ROS at mitochondrial complex I of the respiratory chain, coupled to higher FA $\beta$-oxidation, with concomitant induction of cellular necrosis, features that are diminished by antioxidants [13]. In agreement with these views, the liver of obese NAFLD patients with steatosis exhibits major changes in oxidative stress-related parameters. These include (i) a diminished antioxidant potential (glutathione (GSH) depletion and reduced superoxide dismutase (SOD) activity) [57]; (ii) an increased free-radical activity (higher lipid peroxidation) [57-59], protein oxidation [57], and 3-nitrotyrosine reactivity [60]; (iii) Kupffer-cell activation (increased lipid peroxidation potential and superoxide radical $\left(\mathrm{O}_{2}{ }^{--}\right)$generation, implying NADPH oxidase (NOX2) activation) [61]; (iv) a consequent reduction in the systemic antioxidant capacity of plasma [57] with higher lipid peroxidation indicators [62], thus evidencing the onset of oxidative stress (Figure 1A). Overnutrition-induced ROS generation might represent a triggering mechanism for the onset of insulin resistance $[63,64]$, in addition to the accumulation of lipids 


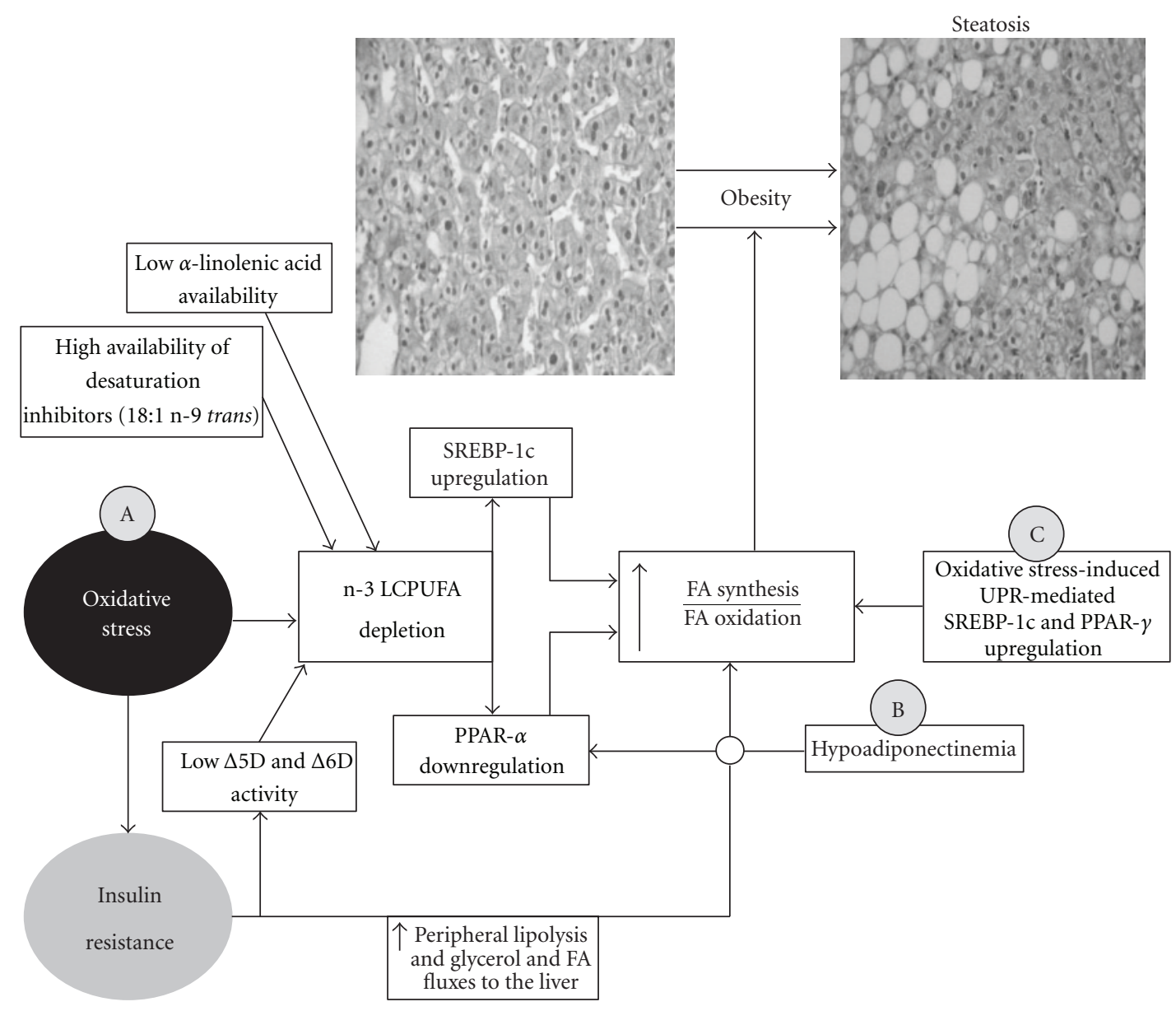

FIGURE 1: Obesity-induced liver oxidative stress (A), hypoadiponectinemia (B), and endoplasmic reticulum stress (C) as factors leading to hepatic steatosis in nonalcoholic fatty liver disease. Abbreviations: $\triangle 5(6) \mathrm{D}$ : delta-5(6) desaturase; FA, fatty acid; LCPUFA: long-chain polyunsaturated fatty acid; PPAR- $\alpha(\gamma)$ : peroxisome proliferator-activated receptor- $\alpha(\gamma)$; SREBP-1c: sterol regulatory element binding protein-1c; UPR: unfolded protein response.

such as free FAs (FFAs) $[65,66]$. This proposal points to the activation of several stress-sensitive serine/threonine kinases by ROS and FFAs, which upon phosphorylation of the insulin receptor and/or the insulin receptor substrate proteins, achieve derangement of insulin-stimulated tyrosine phosphorylation resulting in insulin resistance [63-66].

Development of cellular oxidative stress leads to the production of oxidized products of biomolecules such as DNA bases, aminoacid residues in proteins, and PUFAs in membrane phospholipids [67]. In the latter case, longchain PUFAs (LCPUFAs) of the n-3 series, namely, eicosapentaenoic acid (EPA, 20:5n-3) and docosahexaenoic acid (DHA, 22:6n-3), are the most susceptible to free-radical attack, considering that their respective rate constants for lipid peroxidation initiation are about 7- to 10-fold higher than that for linoleic acid (LA, 18:2n-6) taken as unity [68]. Assessment of the FA pattern of the liver of obese NAFLD patients revealed a significant depletion of LCPUFA n-3 (EPA plus DHA) levels $[51,69,70])$, a parameter that correlates with the levels of LCPUFA n-3 in erythrocytes [69] and that significantly recovers after weight loss [71]. Liver LCPUFA $\mathrm{n}-3$ depletion in obesity may be related to higher utilization due the prevailing high oxidative stress status $[57,72]$ (Figure 1A), a contention that is supported by the significant inverse correlation established between liver phospholipid LCPUFA n-3 content and serum $\mathrm{F}_{2}$-isoprostane levels, as index of free-radical activity (Figure 2(a)). Under these conditions, the nonenzymatic oxidative decomposition of LCPUFA $n-3$ to $\mathrm{J}_{3}$-isoprostane derivatives [73] can occur; however, utilization of LCPUFA $n-3$ by cyclooxygenase-2/5lipoxygenase pathway and/or the cytochrome P450 NADPHdependent epoxygenase system [74] cannot be discarded. In addition to enhanced liver LCPUFA n-3 utilization, depletion of LCPUFA n-3 in NAFLD is associated with defective hepatic capacity for desaturation of the LCPUFA n-3 essential precursor $\alpha$-linolenic acid ( $\alpha$-LA, 18:3n-3). (i) Livers from NAFLD patients show a significant diminution in the hepatic activity of $\Delta-5$ and $\Delta-6$ desaturases $(\Delta-5 \mathrm{D}$ and $\Delta-6 \mathrm{D})$ [75] and in the $(20: 5+22: 6) n-3 / 18: 3 n-3$ product/precursor ratio [51]. These parameters exhibit inversed correlations with the HOMA index [75], pointing to coordinate downregulation of $\Delta-5 \mathrm{D}$ and $\Delta-6 \mathrm{D}$ expression by insulin resistance (Figure 1A) [76, 77]. (ii) Dietary imbalance, as determined by the abdominal adipose tissue PUFA levels as biomarker 


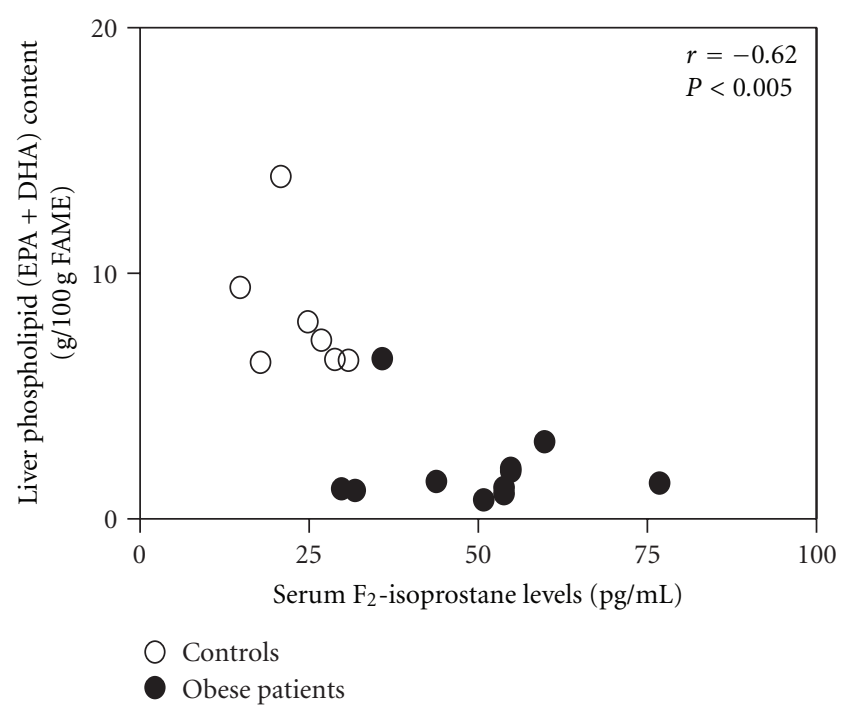

(a)

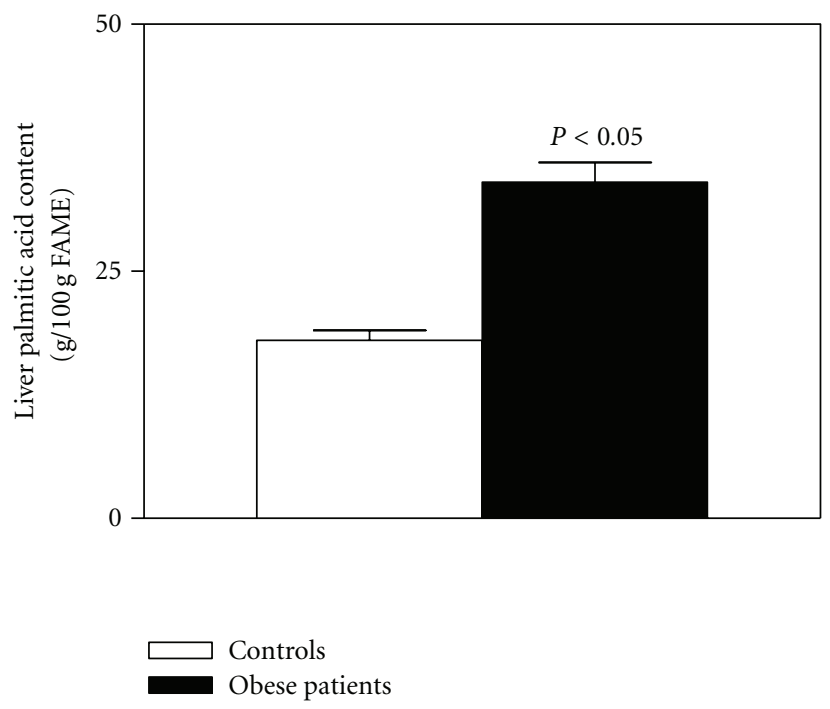

(c)

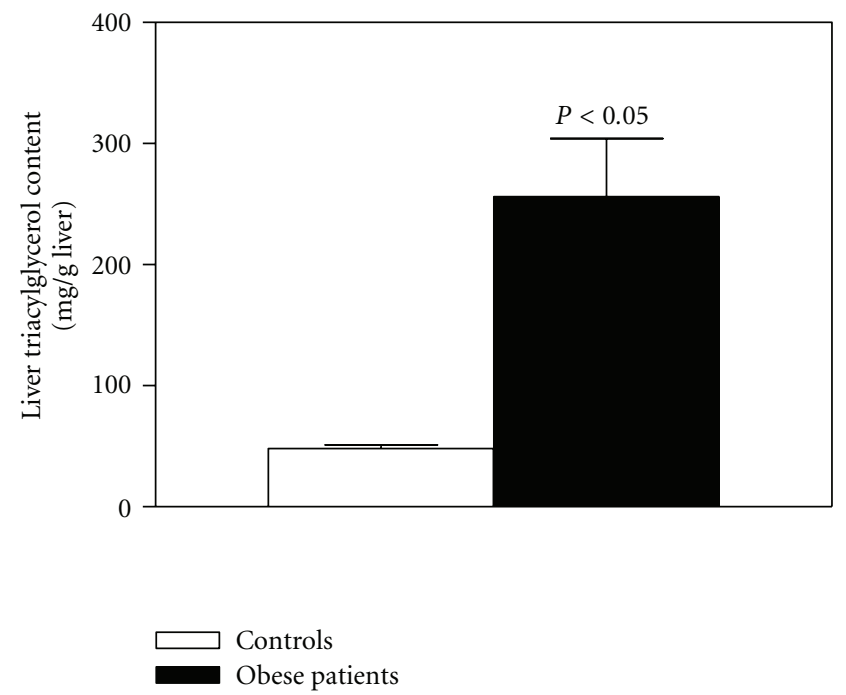

(b)

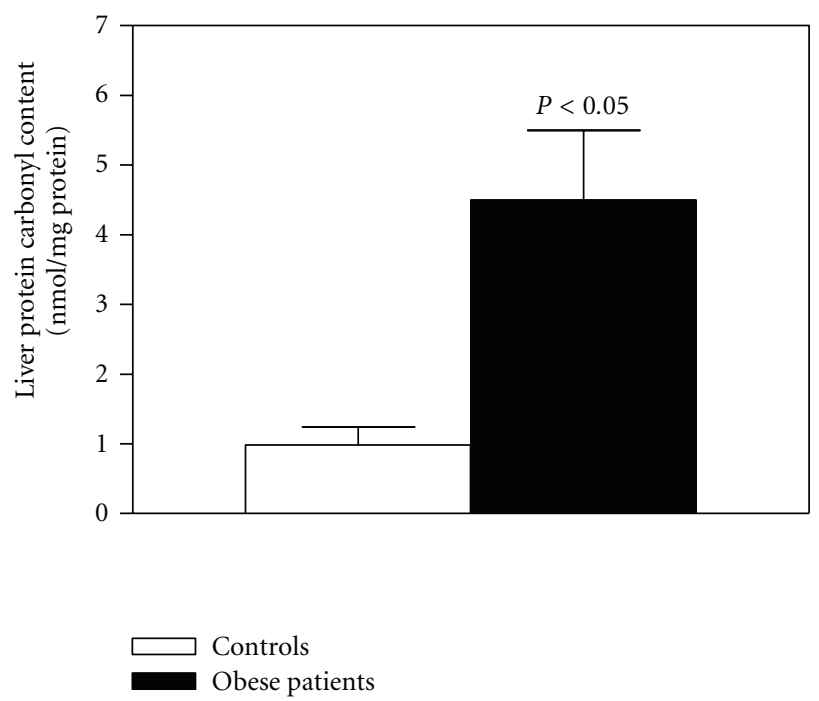

(d)

FIGURE 2: Correlation between liver phospholipid content of LCPUFA n-3 and $\mathrm{F}_{2}$-isoprostane levels in serum as index of oxidative stress (a) and contents of liver triacylglycerols (b), palmitic acid (c), and protein carbonyls (d) in control subjects and obese patients with steatosis. LCPUFA n-3 content corresponds to eicosapentaenoic acid (EPA) plus docosahexaenoic acid (DHA), expressed as g/100 g fatty acid methyl esters (FAME). Correlation in (a) was carried out by Spearman rank order correlation coefficient (unpublished data). Data (means \pm SEM; 10 controls and 8 obese patients with steatosis) presented in (b), (c), and (d) were adapted from Araya et al., 2004 [51].

of dietary intake [78], involves decreased consumption of $\alpha$ LA and higher-than-normal intake of trans FAs (elaidic acid, 18:1n-9 trans), effective $\Delta$-6D inhibitors (Figure 1A) [51].

Under physiological conditions, LCPUFAs $\mathrm{n}-3$ and/or their oxidized metabolites regulate hepatic lipid metabolism acting as (i) ligands of PPAR- $\alpha$ promoting the expression of genes encoding for proteins involved in FA oxidation at mitochondrial, peroxisomal, and microsomal levels, FA binding in cells, and lipoprotein assembly and transport [20] and (ii) downregulators of the lipogenic transcription factor SREBP-1c expression and activation [79-81]. Therefore, LCPUFA $n-3$ depletion in the liver of obese NAFLD patients might favour FA and TAG synthesis over FA oxidation, promoting hepatic steatosis (Figure 1A), with major changes in the mRNA expression of transcription factors controlling liver lipid metabolism. The latter view is evidenced by the increased mRNA expression of SREBP-1c inducing lipogenic genes such as fatty acid synthase (FAS), the concomitant reduction in that of PPAR- $\alpha$ controlling FA oxidation (carnitine palmitoyltransferase-1a; CPT-1a), with the consequent enhancement in the hepatic SREBP-1c/PPAR- $\alpha$ ratios denoting a prolipogenic status [70]. This condition may also involve diminution in TAG export from the liver via very-low density lipoprotein (VLDL) due to decreased production of apolipoprotein B-100 [82], which is upregulated by LCPUFA n-3 and PPAR- $\alpha$ activation $[83,84]$. The above contention 
is further strengthened by the substantial enhancement in the LCPUFA n-6/n-3 ratio observed in liver phospholipids $[73,85]$, considering that LCPUFA $n-3$ are more effective PPAR- $\alpha$ activators than LCPUFA n-6 [79]. In agreement with these findings obtained in the liver, of obese patients, nutritional disequilibrium at the expense of PUFA n-3 in mice subjected to a PUFA n-3 depleted diet-induced hepatic SREBP-1c and lipogenesis up-regulation, with significant depression of FA oxidation and steatosis development [86].

In addition to the prosteatotic mechanism underlying NAFLD with development of oxidative stress and LCPUFA n-3 depletion triggering liver SREBP-1c upregulation and PPAR- $\alpha$ downregulation (Figure 1A), alterations in the signaling pathway of adiponectin may also play a role $[70,87]$ (Figure 1B). Adiponectin, an adipokine secreted by adipocytes in reverse proportion to the body mass index [88], exerts beneficial effects through actions on several tissues, leading to reduction of body fat, improvement of hepatic and peripheral insulin sensitivity, and increased FA oxidation [32, 89]. In the liver, adiponectin binds to the integral membrane proteins AdipoR1 and AdipoR2 acting as receptors for the globular and full-length forms of the adipokine [89]. Although the signaling pathway triggered by adiponectin is not completely understood, current views suggest that most of its cellular effects are mediated by the activation of AMP-activated protein kinase (AMPK) [90]. This is achieved by APPL1 (adaptor protein containing phosphotyrosine binding, pleckstrin homology domains, and leucine zipper 1) that couples adiponectin receptors to AMPK activation [91], with the sequential activation of p38 mitogen-activated protein kinase (p38 MAPK) [92] that phosphorylates PPAR- $\alpha$, thus increasing its association with PPAR- $\alpha$ coactivator $-1 \alpha$ and the transcriptional activity of PPAR- $\alpha$ [93]. Consequently, the expression of PPAR- $\alpha$ target genes encoding for acyl-CoA oxidase, CPT-1a, and fatty acid binding protein 3 is upregulated [91]. Therefore, diminution in the circulating levels of adiponectin [79, 87, 94] and in the hepatic expression of adiponectin and AdipoR2 [95] observed in obese NAFLD patients might contribute to liver PPAR- $\alpha$ downregulation (Figure 1B), representing an alternate reinforcing prolipogenic mechanism in addition to that related to LCPUFA n-3 depletion (Figure 1A).

\section{Liver PPAR-fl Upregulation as a Steatotic Signaling Mechanism}

The specific PPAR subtype PPAR- $\gamma$ is mainly expressed in the white and brown adipose tissue [96], where it controls the expression of genes related to lipogenesis, promoting cell differentiation, FA uptake, and TAG accumulation, which reduces FA delivery to the liver [97]. In the human liver, PPAR- $\gamma$ is expressed at a level that is $9-12 \%$ of that of adipose tissue [35]; however, enhanced expression levels are associated with induction of PPAR- $\gamma$-responsive genes related to lipid metabolism [98]. These include (i) lipoprotein lipase, (ii) proteins involved in FA uptake and intracellular binding and transport, such as FA translocase (FAT/CD36), FA binding proteins 1,4 , and 5 (FABP1, FABP4, and FABP5), and FA transport proteins 2 and 5 (FATP2 and FATP5), and (iii) liver $\mathrm{X}$ receptor, which favours both PPAR- $\gamma$ and FAT/CD36 expression $[14,99]$. Studies in the liver of obese NAFLD patients revealed significant upregulation of PPAR$\gamma$ mRNA levels over those in lean control subjects [94], in agreement with data assessing the PPAR- $\gamma 2$ isoform [100]. Furthermore, liver PPAR- $\gamma$ upregulation coincided with that of SREBP-1c, parameters that showed a significant direct correlation and that constitute a reinforcing lipogenic mechanism [94, 101]. This contention is supported by the differential lipogenic gene expression pattern exhibited by both transcription factors. Under condition of insulin resistance, higher mobilization of nonesterified FAs from peripheral tissues to the liver occurs $[102,103]$, which may be efficiently taken up and subjected to intracellular trafficking for metabolic processing, due to PPAR- $\gamma$-dependent upregulation of liver FAT/CD36 and FATP5, respectively [102]. Thus, enhancement in de novo TAG biosynthesis can be achieved [12, 104], which may be contributed by de novo FA biosynthesis due to SREBP-1c-dependent induction of acetyl-CoA carboxylase, FAS, and stearoyl-CoA desaturase1 observed [94, 105].

Upregulation of liver PPAR- $\gamma$ can be achieved by a liganddependent process including LCPUFA n-3 binding [106]; however, this mechanism does not seem to play a role in obesity-induced PPAR $-\gamma$ activation due to the substantial depletion of LCPUFA n-3 reported [51, 69, 70]. Although development of insulin resistance is likely to involve loss of the regulatory actions of insulin on hepatocellular carbohydrate, protein, and lipid anabolism, FA and TAG biosynthesis is preserved [53, 107]. It is therefore likely that other mechanisms may play a role in the prolipogenic status observed in obese, insulin-resistant, hyperinsulinemic individuals involving PPAR- $\gamma$ and SREBP-1c [70, 92]; the endoplasmic reticulum (ER) stress is one of them [108]. The ER is the cellular compartment for protein synthesis, folding, assembly, and trafficking, as well as for TAG, phospholipid, and sterol biosynthesis [108, 109]. Under several stress conditions, accumulation of abnormally folded proteins triggers the unfolded protein response (UPR), to relieve the ER from the accumulation of misfolded proteins and avoid loss of protein function [108, 109]. A short-lasting UPR reestablishes folding capacity; however, under prolonged or sustained conditions, ER stress changes from cellular survival promotion to liver injury development [108, 110]. The UPR is mediated by three ER transmembrane proteins, namely, (i) double-stranded RNA-activated protein kinase (PKR-) like endoplasmic reticulum kinase (PERK); (ii) inositol requiring enzyme 1 (IRE1); (iii) activating transcription factor 6 (ATF6) $[108,111,112]$. These UPR transducers are normally inhibited by the ER chaperone BiP/Grp78 (binding immunoglobulin protein/glucose regulated protein 78) [113], which upon accumulation of misfolded proteins in the ER lumen dissociates from the luminal domains of PERK, IRE1, and ATF6 allowing their activation [108]. UPR is induced by several stress conditions, including reduced capacity for protein glycosylation or disulfide bond formation, nutrient deprivation, viral infections, and increased FA availability or ROS generation, which led to abnormal 
protein folding $[108,114]$. As already discussed in Section 2, human obesity is characterized by TAG (Figure 2(b)) and saturated FA (palmitic acid; Figure 2(c)) overload in the liver, determining high rates of FA oxidation and ROS generation [3], which is associated with 4-fold increase in hepatic protein carbonylation (Figure 2(d)), as a measure of protein oxidation by ROS [115]. Protein damage by ROS is complex, irreversible and involves various oxidative modifications of amino acid residues in proteins, which may lead to protein unfolding and rapid degradation [115-117]. Thus, under conditions of hepatic palmitate overload (Figure 2(c)) and ROS-dependent protein carbonylation (Figure 2(d)), ER stress is likely to be induced in the liver of obese NAFLD patients. This contention is in agreement with the elevated hepatic levels of BiP/Grp78 and of phosphorylated eukaryotic translation-initiation factor $2 \alpha(\operatorname{eIF} 2 \alpha)$ as components of the PERK signaling pathway $[118,119]$, which are significantly diminished after weight loss [118]. In addition to the liver, adipose tissue from obese patients also exhibits increased parameters related to ER stress, evidencing the activation of the PERK [118, 120], IRE1 [111, 118], and TAF6 [120] signaling pathways. These findings suggest the involvement of the UPR in lipogenesis leading to hepatic steatosis (Figure 1C), in addition to obesityinduced oxidative stress-related LCPUFA n-3 depletion, insulin resistance (Figure 1A), and hypoadiponectinemia (Figure 1B). Interestingly, ER stress has been associated with ROS generation [121] that may contribute to the oxidative stress status developed in the liver of obese patients [3, 57, 72]. The proposed mechanisms involving ER stress induced (i) sustained $\mathrm{Ca}^{2+}$ release from the ER and mitochondrial $\mathrm{Ca}^{2+}$ accumulation with promotion of ROS production [114, 121], and (ii) oxidative folding of nascent proteins by protein disulfide isomerase (PDI) coupled to ER-oxidoreductin 1 (Ero1) operation [114, 121, 122]. However, several important mechanistic questions remain to be addressed regarding the role of UPR in obesity-related liver disease [114] and oxidative stress development [121].

\section{Liver PPAR- $\alpha$ Downregulation: Proinflammatory Connotations}

Liver oxidative stress status, a major mechanism associated with the pathogenesis of steatosis (Figure 1), is exacerbated in obese patients with steatohepatitis (Figure 3). This is evidenced by (i) diminution of hepatic catalase activity, in addition to SOD reduction and GSH depletion already observed in steatosis [57]; (ii) upregulation of the cytochrome P450 2E1 isoform (CYP2E1) and higher in vivo chlorzoxazone hydroxylation catalyzed by CYP2E1, changes that are not observed in steatosis [123]; (iii) further increases in liver nitrotyrosine immunoreactivity [60], hepatic 4hydroxynonenal (marker of lipid peroxidation) and 8hydroxydeoxyguanosine (marker of oxidative DNA damage) immunostaining [124], Kupffer-cell-dependent $\mathrm{O}_{2}{ }^{\bullet-}$ generation, and lipid peroxidation extent [61] (Figure 3). These changes observed in the liver of steatohepatitis subjects are paralleled by a further decrease in the antioxidant capacity of plasma over that in steatosis [57], which correlates with higher systemic levels of lipid peroxidation products [62, 125-127]. Liver oxidative stress in steatohepatitis is related to several contributory factors, including upregulation of the highly prooxidant CYP2E1 [58, 123, 128], hepatic mitochondrial dysfunction $[129,130]$, and mixed inflammatory-cell infiltration and Kupffer-cell activation, involving upregulation of NOX2 [61]. The high prooxidant status attained in steatohepatitis was observed concomitantly with significant enhancement in the DNA binding capacity of hepatic nuclear factor- $\kappa \mathrm{B}(\mathrm{NF}-\kappa \mathrm{B})[131,132]$ and activating protein 1 (AP1) $[131]$, redox-sensitive transcription factors that upregulate the expression of proinflammatory mediators at the Kupffercell level (Figure 3) [3]. These parameters were not modified in patients with simple steatosis, in relation to controls [131].

ROS activate NF- $\kappa \mathrm{B}$ through the classical or canonical inhibitor of $\kappa \mathrm{B}(\mathrm{I} \kappa \mathrm{B})$ kinase (IKK) complex pathway, which depends on NF- $\kappa$ B essential modulator (NEMO) or IKK $\gamma$, IKK $\beta$ activation, nuclear localization of p65-p50 dimers and is associated with inflammation (Figure 3A) [133, 134]. In addition, AP-1 signaling requires de novo synthesis of cJun and c-Fos proteins, followed by phosphorylation of the c-Jun component by activated c-Jun N-terminal kinase (JNK) (Figure 3B), which requires ROS-mediated inhibition of JNK-inactivating phosphatases [135]. At the nuclear level, both NF- $\kappa$ B and AP- 1 may form heterodimers with PPAR$\alpha$, leading to the formation of the transcriptionally inactive complexes p65-PPAR- $\alpha$ and c-Jun-PPAR- $\alpha$ [53]. Thus, obesity-induced diminution in both liver PPAR- $\alpha$ expression and PPAR- $\alpha$ activation related to LCPUFA n-3 depletion may be considered as a proinflammatory mechanism [70], due to the reduced antagonizing action of PPAR- $\alpha$ downregulation on NF- $\kappa \mathrm{B}$ and AP- 1 activation. This contention is supported by the significant inverse correlations established for liver NF- $\kappa$ B and AP- 1 DNA binding with PPAR- $\alpha$ mRNA levels observed in control subjects and obese NAFLD patients with steatohepatitis [136]. Furthermore, significant 7.8-fold and 15.1-fold enhancements in the hepatic NF- $\kappa$ B/PPAR- $\alpha$ and AP-1/PPAR- $\alpha$ ratios are observed in steatohepatitis over control values, respectively, pointing to a major disturbance in signaling pathways triggering a proinflammatory status in the liver of obese patients (Figure 3) [136]. The latter state may be reinforced by three additional mechanisms, namely, (i) TNF- $\alpha$ up-regulation $[61,137-139]$ in response to the initial NF- $\kappa$ B activation, which signals through the TNF$\alpha$ receptor 1 and the canonical pathway and/or by TNF$\alpha$-induced ROS production at the mitochondrial level that activates JNK, enhancing AP-1 DNA binding capacity [133, 134]; (ii) development of endotoxemia [140], with increasing plasma levels of lipopolysaccharide (LPS) triggering tolllike receptor 4 (TLR4) [141], recruitment of several adaptor molecules, and activation of transforming growth factor $\beta$-activated kinase 1 (TAK1) leading to IKK and JNK phosphorylation and NF- $\kappa \mathrm{B}$ and AP-1 activation [141, 142]; (iii) induction of the ER stress, with upregulation of both the PERK/eIF $2 \alpha$ pathway $[118,119]$ achieving NF- $\kappa$ B activation [143] and the IRE1 pathway leading to JNK/AP-1 activation $[111,118,119]$. Although ER stress can activate NF- $\kappa B$ and JNK/AP-1, activation by other mechanisms is also possible, 

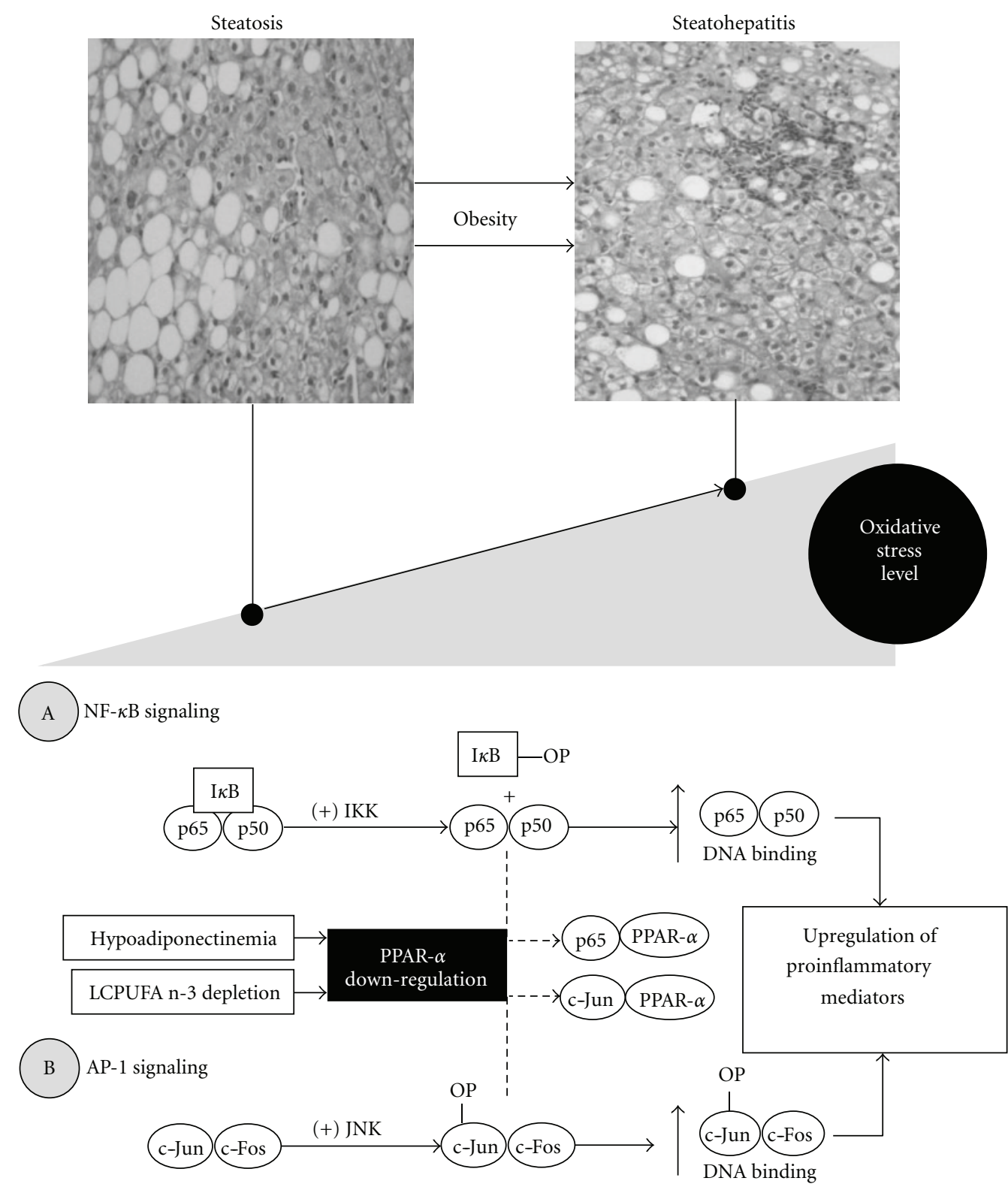

FIGURE 3: Interrelationships between the level of oxidative stress and PPAR- $\alpha$ downregulation in the progression of steatosis to steatohepatitis associated with obesity involving NF- $\kappa \mathrm{B}$ (A) and AP-1 (B) signaling. Abbreviations: AP-1: activating protein-1 (c-Jun-cFos; c-Jun-OP, phosphorylated c-Jun); I $\kappa$ B: inhibitor of $\kappa \mathrm{B}$ (I $\kappa \mathrm{B}-\mathrm{OP}$, phosphorylated I $\kappa \mathrm{B})$; IKK: I $\kappa \mathrm{B}$ kinase; JNK: c-Jun N-terminal kinase; LCPUFA, longchain polyunsaturated fatty acid; NF- $\kappa$ B: nuclear factor- $\kappa \mathrm{B}$ (p65-p50); PPAR- $\alpha$ : peroxisome proliferator-activated receptor- $\alpha$. Solid arrows indicate enhanced contribution, whereas broken arrows indicate reduced contribution.

and further studies are needed to establish their relative importance in the development of steatohepatitis in human obesity.

\section{Conclusions}

Prolonged liver oxidative stress in human obesity is associated with development of a wide disease spectrum ranging from steatosis to steatosis with inflammation, fibrosis, and cirrhosis (nonalcoholic steatohepatitis), a redox imbalance showing a functional interdependency with insulin resistance [3]. Disease mechanisms might involve (i) the initial
ROS production due to lipotoxicity with the onset of steatosis (Figure 1); (ii) exacerbation of ROS generation due to concurrence of mitochondrial dysfunction, microsomal CYP2E1 induction, and inflammatory-cell activation (Figure 3). Misregulation of inflammatory cytokine, adipokine, and chemokine signaling may reinforce the initial mechanisms of ROS production and insulin resistance, representing determinant factors in the progression of steatosis to steatohepatitis. In this setting, alterations in the expression and/or activation in hepatic PPARs may play crucial pathogenic roles, considering their importance in energy homeostasis and inflammation [106]. 
Liver PPAR- $\alpha$ downregulation and substantial enhancement in the hepatic SREBP-1c/PPAR- $\alpha$ mRNA content ratio represent major metabolic disturbances between de novo lipogenesis and FA oxidation favouring the former, as a central issue triggering liver steatosis in obesity-induced oxidative stress and insulin resistance. The prosteatotic action of PPAR- $\alpha$ downregulation may be reinforced by PPAR$\gamma$ upregulation favouring hepatic FA uptake, binding, and transport, representing a complementary lipogenic mechanism to SREBP-1c induction leading to de novo FA synthesis and TAG accumulation. In addition, PPAR- $\alpha$ downregulation may play a significant role in enhancing the DNA binding capacity of proinflammatory factors NF- $\kappa \mathrm{B}$ and AP1 in the liver of obese patients, thus constituting one of the major mechanisms for the progression of simple steatosis to steatohepatitis. In the past, PPARs have been studied as drug targets for the management of NAFLD in obesity and the broader MetS [53]. However, PPAR- $\alpha$ agonists such as fibrates used to diminish steatosis and inflammatory scores in human steatohepatitis revealed poor effectiveness, thiazolidinediones have weight gain limitations, whereas that of dual PPAR- $\alpha \gamma$ agonists has safety concerns [53]. Considering the negative correlation established between liver SREBP-1c/PPAR- $\alpha$ ratios and LCPUFA n-3 levels in control and obese subjects [70], which points to liver LCPUFA n-3 depletion as a major factor directing FAs toward TAG storage, LCPUFA n-3 supplementation was used as PPAR- $\alpha$ targeting. Supplementation with either fish oil, seal oil, or purified LCPUFA n-3 diminished steatosis scores, as evidenced by ultrasonography [144-147] or by determination of lipid content in posttreatment liver biopsies [148]. Furthermore, improvement in liver function markers [144-148], TAGs [145, 146] and TNF- $\alpha$ [145] levels in serum were observed after LCPUFA n-3 administration. These data were recently included in a larger meta-analysis comprising nine studies involving 355 individuals, which concluded that LCPUFA n-3 supplementation in human NAFLD patients is associated with a positive effect on liver fat [149]. In addition, positive anti-inflammatory outcome is also observed [144-148], which may include (i) PPAR$\alpha$ activation and further inhibitory action on NF- $\kappa \mathrm{B}$ and AP-1 signaling [150]; (ii) EPA and DHA metabolism by the cyclooxygenase-2/5-lipoxygenase pathway to produce $\mathrm{E}(\mathrm{D})$ resolvins and protectin D1 as anti-inflammatory mediators [151]; (iii) EPA and DHA oxygenation by cytochrome P450 NADPH-dependent epoxygenases, with production of epoxy derivatives with potent anti-inflammatory effects [151]. LCPUFA n-3 effects on liver inflammation and fibrosis are being currently addressed by several clinical trials [152].

\section{Conflict of Interests}

The authors have declared that no conflict of interests exists.

\section{Acknowledgment}

This work was supported by Grant 1120034 from the National Commission for Scientific and Technological Research (FONDECYT) (Chile).

\section{References}

[1] M. R. Charlton, J. M. Burns, R. A. Pedersen, K. D. Watt, J. K. Heimbach, and R. A. Dierkhising, "Frequency and outcomes of liver transplantation for nonalcoholic steatohepatitis in the United States," Gastroenterology, vol. 141, no. 4, pp. 12491253, 2011.

[2] C. D. Byrne, "Non-alcoholic fatty liver disease, insulin resistance and ectopic fat: a new problem in diabetes management," Diabetic Medicine, vol. 29, no. 9, pp. 1098-1107, 2012, Dorothy Hodgkin Lecture 2012.

[3] L. A. Videla, R. Rodrigo, J. Araya, and J. Poniachik, "Insulin resistance and oxidative stress interdependency in nonalcoholic fatty liver disease," Trends in Molecular Medicine, vol. 12, no. 12, pp. 555-558, 2006.

[4] S. Saadeh, Z. M. Younossi, E. M. Remer et al., "The utility of radiological imaging in nonalcoholic fatty liver disease," Gastroenterology, vol. 123, no. 3, pp. 745-750, 2002.

[5] A. L. Fracanzani, L. Valenti, E. Bugianesi et al., "Risk of severe liver disease in nonalcoholic fatty liver disease with normal aminotransferase levels: a role for insulin resistance and diabetes," Hepatology, vol. 48, no. 3, pp. 792-798, 2008.

[6] J. D. Browning, L. S. Szczepaniak, R. Dobbins et al., "Prevalence of hepatic steatosis in an urban population in the United States: impact of ethnicity," Hepatology, vol. 40, no. 6, pp. 1387-1395, 2004.

[7] V. Ratziu, S. Bellentani, H. Cortez-Pinto, C. Day, and G. Marchesini, "A position statement on NAFLD/NASH based on the EASL 2009 special conference," Journal of Hepatology, vol. 53, no. 2, pp. 372-384, 2010.

[8] J. B. Schwimmer, R. Deutsch, T. Kahen, J. E. Lavine, C. Stanley, and C. Behling, "Prevalence of fatty liver in children and adolescents," Pediatrics, vol. 118, no. 4, pp. 1388-1393, 2006.

[9] R. Stienstra, C. Duval, M. Müller, and S. Kersten, "PPARs, obesity, and inflammation," PPAR Research, vol. 2007, Article ID 95974, 10 pages, 2007.

[10] A. Kotronen, A. Seppälä-Lindroos, R. Bergholm, and H. YkiJärvinen, "Tissue specificity of insulin resistance in humans: fat in the liver rather than muscle is associated with features of the metabolic syndrome," Diabetologia, vol. 51, no. 1, pp. 130-138, 2008.

[11] G. Musso, R. Gambino, and M. Cassader, "Recent insights into hepatic lipid metabolism in non-alcoholic fatty liver disease (NAFLD)," Progress in Lipid Research, vol. 48, no. 1, pp. 1-26, 2009.

[12] K. L. Donnelly, C. I. Smith, S. J. Schwarzenberg, J. Jessurun, M. D. Boldt, and E. J. Parks, "Sources of fatty acids stored in liver and secreted via lipoproteins in patients with nonalcoholic fatty liver disease," Journal of Clinical Investigation, vol. 115, no. 5, pp. 1343-1351, 2005.

[13] A. Aronis, Z. Madar, and O. Tirosh, "Mechanism underlying oxidative stress-mediated lipotoxicity: exposure of J774.2 macrophages to triacylglycerols facilitates mitochondrial reactive oxygen species production and cellular necrosis," Free Radical Biology and Medicine, vol. 38, no. 9, pp. 12211230, 2005.

[14] S. J. Bensinger and P. Tontonoz, "Integration of metabolism and inflammation by lipid-activated nuclear receptors," Nature, vol. 454, no. 7203, pp. 470-477, 2008.

[15] J. P. Berger, T. E. Akiyama, and P. T. Meinke, "PPARs: therapeutic targets for metabolic disease," Trends in Pharmacological Sciences, vol. 26, no. 5, pp. 244-251, 2005. 
[16] L. Michalik, J. Auwerx, J. P. Berger et al., "International union of pharmacology. LXI. Peroxisome proliferator-activated receptors," Pharmacological Reviews, vol. 58, no. 4, pp. 726 741, 2006.

[17] M. A. Lazar, "PPAR $\gamma, 10$ years later," Biochimie, vol. 87, no. 1, pp. 9-13, 2005.

[18] F. A. Batista, D. B. Trivella, A. Bernardes, J. Gratieri, P. S. Oliveira, A. C. Figueira et al., "Structural insights into human peroxisome proliferator activated receptor delta (PPARdelta) selective ligand binding," PLoS One, vol. 7, no. 5, Article ID e33643, 2012.

[19] B. Desvergne and W. Wahli, "Peroxisome proliferatoractivated receptors: nuclear control of metabolism," Endocrine Reviews, vol. 20, no. 5, pp. 649-688, 1999.

[20] S. Kersten, B. Desvergne, and W. Wahli, "Roles of PPARS in health and disease," Nature, vol. 405, no. 6785, pp. 421-424, 2000.

[21] M. Rakhshandehroo, B. Knoch, M. Müller, and S. Kersten, "Peroxisome proliferator-activated receptor alpha target genes," PPAR Research, vol. 2010, Article ID 612089, 20 pages, 2010.

[22] C. N. A. Palmer, M. H. Hsu, K. J. Griffin, J. L. Raucy, and E. F. Johnson, "Peroxisome proliferator activated receptor- $\alpha$ expression in human liver," Molecular Pharmacology, vol. 53, no. 1, pp. 14-22, 1998.

[23] M. Rakhshandehroo, G. Hooiveld, M. Müller, and S. Kersten, "Comparative analysis of gene regulation by the transcription factor PPAR $\alpha$ between mouse and human," PLoS ONE, vol. 4, no. 8, Article ID e6796, 2009.

[24] P. Gervois, I. Pineda Torra, G. Chinetti et al., "A truncated human peroxisome proliferator-activated receptor $\alpha$ splice variant with dominant negative activity," Molecular Endocrinology, vol. 13, no. 9, pp. 1535-1549, 1999.

[25] S. Chen, Y. Li, S. Li, and C. Yu, "A Val227Ala substitution in the peroxisome proliferator activated receptor alpha (PPAR alpha) gene associated with non-alcoholic fatty liver disease and decreased waist circumference and waist-to-hip ratio," Journal of Gastroenterology and Hepatology, vol. 23, no. 9, pp. 1415-1418, 2008.

[26] P. Dongiovanni, R. Rametta, A. L. Fracanzani et al., "Lack of association between peroxisome proliferator-activated receptors alpha and gamma2 polymorphisms and progressive liver damage in patients with non-alcoholic fatty liver disease: a case control study," BMC Gastroenterology, vol. 10, article 102, 2010.

[27] K. Schoonjans, B. Staels, and J. Auwerx, "Role of the peroxisome proliferator-activated receptor (PPAR) in mediating the effects of fibrates and fatty acids on gene expression," Journal of Lipid Research, vol. 37, no. 5, pp. 907-925, 1996.

[28] S. A. Kliewer, S. S. Sundseth, S. A. Jones et al., "Fatty acids and eicosanoids regulate gene expression through direct interactions with peroxisome proliferator-activated receptors $\alpha$ and $\gamma$," Proceedings of the National Academy of Sciences of the United States of America, vol. 94, no. 9, pp. 4318-4323, 1997.

[29] S. Luquet, J. Lopez-Soriano, D. Holst et al., "Roles of peroxisome proliferator-activated receptor delta $(\operatorname{PPAR} \delta)$ in the control of fatty acid catabolism. A new target for the treatment of metabolic syndrome," Biochimie, vol. 86, no. 11, pp. 833-837, 2004.

[30] L. Dubuquoy, S. Dharancy, S. Nutten, S. Pettersson, J. Auwerx, and P. Desreumaux, "Role of peroxisome proliferatoractivated receptor $\gamma$ and retinoid $\mathrm{X}$ receptor heterodimer in hepatogastroenterological diseases," The Lancet, vol. 360, no. 9343, pp. 1410-1418, 2002.
[31] F. Damiano, G. V. Gnoni, and L. Siculella, "Citrate carrier promoter is target of peroxisome proliferator-activated receptor alpha and gamma in hepatocytes and adipocytes," International Journal of Biochemistry \& Cell Biology, vol. 44, no. 4, pp. 659-668, 2012.

[32] Y. Wang, K. S. L. Lam, M. H. Yau, and A. Xu, "Post-translational modifications of adiponectin: mechanisms and functional implications," Biochemical Journal, vol. 409, no. 3, pp. 623-633, 2008.

[33] A. Tailleux, K. Wouters, and B. Staels, "Roles of PPARs in NAFLD: potential therapeutic targets," Biochimica Et Biophysica Acta, vol. 1821, no. 5, pp. 809-818, 2012.

[34] Y. X. Wang, "PPARs: diverse regulators in energy metabolism and metabolic diseases," Cell Research, vol. 20, no. 2, pp. 124$137,2010$.

[35] A. J. Vidal-Puig, R. V. Considine, M. Jimenez-Liñan et al., "Peroxisome proliferator-activated receptor gene expression in human tissues: effects of obesity, weight loss, and regulation by insulin and glucocorticoids," Journal of Clinical Investigation, vol. 99, no. 10, pp. 2416-2422, 1997.

[36] K. H. Kim, S. P. Hong, K. Kim, M. J. Park, K. J. Kim, and J. Cheong, "HCV core protein induces hepatic lipid accumulation by activating SREBP1 and PPAR $\gamma$," Biochemical and Biophysical Research Communications, vol. 355, no. 4, pp. 883-888, 2007.

[37] K. H. Kim, H. J. Shin, K. Kim et al., "Hepatitis B Virus X Protein Induces Hepatic Steatosis Via Transcriptional Activation of SREBP1 and PPAR $y$," Gastroenterology, vol. 132, no. 5, pp. 1955-1967, 2007.

[38] K. Kim, K. H. Kim, E. Ha, J. Y. Park, N. Sakamoto, and J. Cheong, "Hepatitis C virus NS5A protein increases hepatic lipid accumulation via induction of activation and expression of PPARgamma," FEBS Letters, vol. 583, no. 17, pp. 27202726, 2009.

[39] S. Gawrieh, M. C. Marion, R. Komorowski, J. Wallace, M. Charlton, A. Kissebah et al., "Genetic variation in the peroxisome proliferator activated receptor-gamma gene is associated with histologically advanced NAFLD," Digestive Diseases and Sciences, vol. 57, no. 4, pp. 952-957, 2012.

[40] Z. Yang, J. Wen, Q. Li, X. Tao, Z. Ye, M. He et al., "PPARG gene Pro12Ala variant contributes to the development of non-alcoholic fatty liver in middle-aged and older Chinese population," Molecular and Cellular Endocrinology, vol. 348, no. 1, pp. 255-259, 2012.

[41] S. S. Deeb, L. Fajas, M. Nemoto et al., "A Pro12Ala substitution in PPAR 22 associated with decreased receptor activity, lower body mass index and improved insulin sensitivity," Nature Genetics, vol. 20, no. 3, pp. 284-287, 1998.

[42] D. Altshuler, J. N. Hirschhorn, M. Klannemark et al., "The common PPAR $\gamma$ Pro12Ala polymorphism is associated with decreased risk of type 2 diabetes," Nature Genetics, vol. 26, no. 1, pp. 76-80, 2000.

[43] A. S. F. Doney, B. Fischer, J. E. Cecil et al., "Association of the Pro12Ala and C1431T variants of PPARG and their haplotypes with susceptibility to Type 2 diabetes," Diabetologia, vol. 47 , no. 3, pp. 555-558, 2004.

[44] W. R. Oliver, J. L. Shenk, M. R. Snaith et al., "A selective peroxisome proliferator-activated receptor $\delta$ agonist promotes reverse cholesterol transport," Proceedings of the National Academy of Sciences of the United States of America, vol. 98, no. 9, pp. 5306-5311, 2001.

[45] S. Liu, B. Hatano, M. Zhao et al., "Role of peroxisome proliferator-activated receptor $\delta / \beta$ in hepatic metabolic 
regulation," Journal of Biological Chemistry, vol. 286, no. 2, pp. 1237-1247, 2011.

[46] U. Risérus, D. Sprecher, T. Johnson et al., "Activation of peroxisome proliferator-activated receptor (PPAR) $\delta$ promotes reversal of multiple metabolic abnormalities, Reduces oxidative stress, and increases fatty acid oxidation in moderately obese men," Diabetes, vol. 57, no. 2, pp. 332-339, 2008.

[47] E. M. Ooi, G. F. Watts, D. L. Sprecher, D. C. Chan, and P. H. Barrett, "Mechanism of action of a peroxisome proliferatoractivated receptor (PPAR)-delta agonist on lipoprotein metabolism in dyslipidemic subjects with central obesity," Journal of Clinical Endocrinology \& Metabolism, vol. 96, no. 10, pp. 1568-1576, 2011.

[48] H. E. Bays, S. Schwartz, T. Littlejohn III, B. Kerzner, R. M. Krauss, D. B. Karpf et al., "MBX-8025, a novel peroxisome proliferator receptor delta agonist: lipid and other metabolic effects in dyslipidemic overweight patients treated with and without atorvastatin," Journal of Clinical Endocrinology \& Metabolism, vol. 96, no. 9, pp. 2889-2289, 2011.

[49] Y. J. Choi, B. K. Roberts, X. Wang, J. C. Geaney, S. Naim, K. Wojnoonski K et al., "Effects ofthe PPAR- $\sigma$ agonist MBX8025 on atherogenic dyslipidemia," Atherosclerosis, vol. 220, no. 2, pp. 470-476, 2012.

[50] L. Serrano-Marco, M. R. Chacón, E. Maymó-Masip, E. Barroso, L. Salvadó, M. Wabistch et al., "TNF- $\alpha$ inhibits PPAR $\beta$ / $\sigma$ activity and SIRT1 expression through NF- $\kappa$ B in human adipocytes," Biochimica Et Biophysica Acta, vol. 1821, no. 9, pp. 1177-1185, 2012.

[51] J. Araya, R. Rodrigo, L. A. Videla et al., "Increase in longchain polyunsaturated fatty acid $n-6 / n-3$ ratio in relation to hepatic steatosis in patients with non-alcoholic fatty liver disease," Clinical Science, vol. 106, no. 6, pp. 635-643, 2004.

[52] M. R. Kashi, D. M. Torres, and S. A. Harrison, "Current and emerging therapies in nonalcoholic fatty liver disease," Seminars in Liver Disease, vol. 28, no. 4, pp. 396-406, 2008.

[53] J. George and C. Liddle, "Nonalcoholic fatty liver disease: pathogenesis and potential for nuclear receptors as therapeutic targets," Molecular Pharmaceutics, vol. 5, no. 1, pp. 49-59, 2008.

[54] S. Gawrieh, E. C. Opara, and T. R. Koch, "Oxidative stress in nonalcoholic fatty liver disease: pathogenesis and antioxidant therapies," Journal of Investigative Medicine, vol. 52, no. 8, pp. 506-514, 2004.

[55] H. Sies, W. Stahl, and A. Sevanian, "Nutritional, dietary and postprandial oxidative stress," Journal of Nutrition, vol. 135, no. 5, pp. 96-972, 2005.

[56] J. D. McGarry and D. W. Foster, "Regulation of hepatic fatty acid oxidation and ketone body production," Annual Review of Biochemistry, vol. 49, pp. 395-420, 1980.

[57] L. A. Videla, R. Rodrigo, M. Orellana et al., "Oxidative stressrelated parameters in the liver of non-alcoholic fatty liver disease patients," Clinical Science, vol. 106, no. 3, pp. 261268, 2004.

[58] L. Malaguarnera, R. Madeddu, E. Palio, N. Arena, and M. Malaguarnera, "Heme oxygenase-1 levels and oxidative stress-related parameters in non-alcoholic fatty liver disease patients," Journal of Hepatology, vol. 42, no. 4, pp. 585-591, 2005.

[59] C. P. M. S. Oliveira, J. Faintuch, A. Rascovski et al., "Lipid peroxidation in bariatric candidates with nonalcoholic fatty liver disease (NAFLD)—preliminary findings," Obesity Surgery, vol. 15, no. 4, pp. 502-505, 2005.
[60] A. J. Sanyal, C. Campbell-Sargent, F. Mirshahi et al., "Nonalcoholic steatohepatitis: association of insulin resistance and mitochondrial abnormalities," Gastroenterology, vol. 120, no. 5, pp. 1183-1192, 2001.

[61] L. Malaguarnera, M. Di Rosa, A. M. Zambito, N. Dell'Ombra, F. Nicoletti, and M. Malaguarnera, "Chitotriosidase gene expression in Kupffer cells from patients with non-alcoholic fatty liver disease," Gut, vol. 55, no. 9, pp. 1313-1320, 2006.

[62] C. Loguercio, V. De Girolamo, I. De Sio et al., "Nonalcoholic fatty liver disease in an area of southern italy: main clinical, histological, and pathophysiological aspects," Journal of Hepatology, vol. 35, no. 5, pp. 568-574, 2001.

[63] J. L. Evans, B. A. Maddux, and I. D. Goldfine, "The molecular basis for oxidative stress-induced insulin resistance," Antioxidants and Redox Signaling, vol. 7, no. 7-8, pp. 1040-1052, 2005.

[64] N. Houstis, E. D. Rosen, and E. S. Lander, "Reactive oxygen species have a causal role in multiple forms of insulin resistance," Nature, vol. 440, no. 7086, pp. 944-948, 2006.

[65] C. Yu, Y. Chen, G. W. Cline et al., "Mechanism by which fatty acids inhibit insulin activation of insulin receptor substrate1 (IRS-1)-associated phosphatidylinositol 3-kinase activity in muscle," Journal of Biological Chemistry, vol. 277, no. 52, pp. 50230-50236, 2002.

[66] S. Neschen, K. Morino, L. E. Hammond et al., "Prevention of hepatic steatosis and hepatic insulin resistance in mitochondrial acyl-CoA:glycerol-sn-3-phosphate acyltransferase 1 knockout mice," Cell Metabolism, vol. 2, no. 1, pp. 55-65, 2005.

[67] H. Sies, "Biochemistry of oxidative stress," Angewandte Chemie, vol. 25, pp. 1058-1071, 1986.

[68] L. A. Witting, "Lipid peroxidation in vivo," Journal of the American Oil Chemists Society, vol. 42, no. 11, pp. 908-913, 1965.

[69] A. Elizondo, J. Araya, R. Rodrigo et al., "Polyunsaturated fatty acid pattern in liver and erythrocyte phospholipids from obese patients," Obesity, vol. 15, no. 1, pp. 24-31, 2007.

[70] P. Pettinelli, T. del Pozo, J. Araya et al., "Enhancement in liver SREBP-1c/PPAR- $\alpha$ ratio and steatosis in obese patients: correlations with insulin resistance and n-3 long-chain polyunsaturated fatty acid depletion," Biochimica et Biophysica Acta, vol. 1792, no. 11, pp. 1080-1086, 2009.

[71] A. Elizondo, J. Araya, R. Rodrigo et al., "Effects of weight loss on liver and erythrocyte polyunsaturated fatty acid pattern and oxidative stress status in obese patients with nonalcoholic fatty liver disease," Biological Research, vol. 41, no. 1, pp. 59-68, 2008.

[72] L. A. Videla, R. Rodrigo, J. Araya, and J. Poniachik, "Oxidative stress and depletion of hepatic long-chain polyunsaturated fatty acids may contribute to nonalcoholic fatty liver disease," Free Radical Biology and Medicine, vol. 37, no. 9, pp. 1499-1507, 2004.

[73] L. Gao, J. Wang, K. R. Sekhar et al., "Novel n-3 fatty acid oxidation products activate $\mathrm{Nrf} 2$ by destabilizing the association between Keap1 and Cullin3," Journal of Biological Chemistry, vol. 282, no. 4, pp. 2529-2537, 2007.

[74] V. Fernández, G. Tapia, and L. A. Videla, "Recent advances in liver preconditioning: thyroid hormone, n-3 long-chain polyunsaturated fatty acids and iron," World Journal of Hepatology, vol. 4, no. 4, pp. 119-128, 2012.

[75] J. Araya, R. Rodrigo, P. Pettinelli, A. V. Araya, J. Poniachik, and L. A. Videla, "Decreased liver fatty Acid $\delta-6$ and $\delta-5$ desaturase activity in obese patients," Obesity, vol. 18, no. 7, pp. 1460-1463, 2010. 
[76] M. T. Nakamura and T. Y. Nara, "Structure, function, and dietary regulation of $\Delta 6, \Delta 5$, and $\Delta 9$ desaturases," Annual Review of Nutrition, vol. 24, pp. 345-376, 2004.

[77] J. G. Gormaz, R. Rodrigo, L. A. Videla, and M. Beems, "Biosynthesis and bioavailability of long-chain polyunsaturated fatty acids in non-alcoholic fatty liver disease," Progress in Lipid Research, vol. 49, no. 4, pp. 407-419, 2010.

[78] A. Baylin, E. K. Kabagambe, X. Siles, and H. Campos, "Adipose tissue biomarkers of fatty acid intake," American Journal of Clinical Nutrition, vol. 76, no. 4, pp. 750-757, 2002.

[79] S. D. Clarke, "Nonalcoholic Steatosis and Steatohepatitis. I. Molecular mechanism for polyunsaturated fatty acid regulation of gene transcription," American Journal of Physiology, vol. 281, no. 4, pp. G865-G869, 2001.

[80] D. B. Jump, D. Botolin, Y. Wang, J. Xu, B. Christian, and O. Demeure, "Fatty acid regulation of hepatic gene transcription," Journal of Nutrition, vol. 135, no. 11, pp. 2503-2506, 2005.

[81] Y. B. Lombardo and A. G. Chicco, "Effects of dietary polyunsaturated n-3 fatty acids on dyslipidemia and insulin resistance in rodents and humans. A review," Journal of Nutritional Biochemistry, vol. 17, no. 1, pp. 1-13, 2006.

[82] M. Charlton, R. Sreekumar, D. Rasmussen, K. Lindor, and K. S. Nair, "Apolipoprotein synthesis in nonalcoholic steatohepatitis," Hepatology, vol. 35, no. 4, pp. 898-904, 2002.

[83] C. Meunier-Durmort, H. Poirier, I. Niot, C. Forest, and P. Besnard, "Up-regulation of the expression of the gene for liver fatty acid-binding protein by long-chain fatty acids," Biochemical Journal, vol. 319, no. 2, pp. 483-487, 1996.

[84] L. Carlsson, D. Lindén, M. Jalouli, and J. Oscarsson, "Effects of fatty acids and growth hormone on liver fatty acid binding protein and PPAR $\alpha$ in rat liver," American Journal of Physiology, vol. 281, no. 4, pp. E772-E781, 2001.

[85] R. Valenzuela and L. A. Videla, "The importance of the longchain polyunsaturated fatty acid $n-6 / n-3$ ratio in development of non-alcoholic fatty liver associated with obesity," Food and Function, vol. 2, no. 11, pp. 644-648, 2011.

[86] B. D. Pacchikian, A. Essaghir, J. B. Demoulin et al., "Hepatic n-3 polyunsaturated fatty acid depletion promotes steatosis and insulin resistance in mice: genomic analysis of cellular targets," PLos ONE, vol. 6, no. 8, Article ID e23365, 2011.

[87] C. Pagano, G. Soardo, W. Esposito et al., "Plasma adiponectin is decreased in nonalcoholic fatty liver disease," European Journal of Endocrinology, vol. 152, no. 1, pp. 113-118, 2005.

[88] Y. Arita, S. Kihara, N. Ouchi et al., "Paradoxical decrease of an adipose-specific protein, adiponectin, in obesity," Biochemical and Biophysical Research Communications, vol. 257, no. 1, pp. 79-83, 1999.

[89] M. J. Czaja, "Liver injury in the setting of steatosis: crosstalk between adipokine and cytokine," Hepatology, vol. 40, no. 1, pp. 19-22, 2004.

[90] T. Kadowaki, T. Yamauchi, and N. Kubota, "The physiological and pathophysiological role of adiponectin and adiponectin receptors in the peripheral tissues and CNS," FEBS Letters, vol. 582, no. 1, pp. 74-80, 2008.

[91] X. Mao, C. K. Kikani, R. A. Riojas et al., "APPL1 binds to adiponectin receptors and mediates adiponectin signalling and function," Nature Cell Biology, vol. 8, no. 5, pp. 516-523, 2006.

[92] M. J. Yoon, G. Y. Lee, J. J. Chung, Y. - H. Ahn, S. H. Hong, and J. B. Kim, "Adiponectin increases fatty acid oxidation in skeletal muscle cells by sequential activation of AMP-activated protein kinase, p38 mitogen-activated protein kinase, and peroxisome proliferator-activated receptor $\alpha$," Diabetes, vol. 55, no. 9, pp. 2562-2570, 2006.

[93] P. M. Barger, A. C. Browning, A. N. Garner, and D. P. Kelly, "p38 mitogen-activated protein kinase activates peroxisome proliferator-activated receptor $\alpha$ : a potential role in the cardiac metabolic stress response," Journal of Biological Chemistry, vol. 276, no. 48, pp. 44495-44501, 2001.

[94] P. Pettinelli and L. A. Videla, "Up-regulation of PPAR- $\gamma$ mRNA expression in the liver of obese patients: an additional reinforcing lipogenic mechanism to SREBP-1c induction," Journal of Clinical Endocrinology and Metabolism, vol. 96, no. 5, pp. 1424-1430, 2011.

[95] S. Kaser, A. Maschen, A. Cayon et al., "Adiponectin and its receptors in non-alcoholic steatohepatitis," Gut, vol. 54, no. 1, pp. 117-121, 2005.

[96] M. D. Neher, S. Weckbach, M. S. Huber-Lang, and P. F. Stahel, "New insights into the role of peroxisome proliferatoractivated receptors in regulating the inflammatory response after tissue injury," PPAR Research, vol. 2012, Article ID 728461, 13 pages, 2012.

[97] E. R. Kallwitz, A. McLachlan, and S. J. Cotler, "Role of peroxisome proliferators-activated receptors in the pathogenesis and treatment of nonalcoholic fatty liver disease," World Journal of Gastroenterology, vol. 14, no. 1, pp. 22-28, 2008.

[98] U. A. Boelsterli and M. Bedoucha, "Toxicological consequences of altered peroxisome proliferator-activated receptor $\gamma(\operatorname{PPAR} \gamma)$ expression in the liver: insights from models of obesity and type 2 diabetes," Biochemical Pharmacology, vol. 63, no. 1, pp. 1-10, 2002.

[99] D. Greco, A. Kotronen, J. Westerbacka et al., "Gene expression in human NAFLD," American Journal of Physiology, vol. 294, no. 5, pp. G1281-G1287, 2008.

[100] J. Westerbacka, M. Kolak, T. Kiviluoto et al., "Genes involved in fatty acid partitioning and binding, lipolysis, monocyte/macrophage recruitment, and inflammation are overexpressed in the human fatty liver of insulin-resistant subjects," Diabetes, vol. 56, no. 11, pp. 2759-2765, 2007.

[101] R. Marfella, C. Di Filippo, M. Portoghese et al., "Myocardial lipid accumulation in patients with pressure-overloaded heart and metabolic syndrome," Journal of Lipid Research, vol. 50, no. 11, pp. 2314-2323, 2009.

[102] S. Nielsen, Z. Guo, C. M. Johnson, D. D. Hensrud, and M. D. Jensen, "Splanchnic lipolysis in human obesity," Journal of Clinical Investigation, vol. 113, no. 11, pp. 1582-1588, 2004.

[103] E. Fabbrini, B. S. Mohammed, F. Magkos, K. M. Korenblat, B. W. Patterson, and S. Klein, "Alterations in adipose tissue and hepatic lipid kinetics in obese men and women with nonalcoholic fatty liver disease," Gastroenterology, vol. 134, no. 2, pp. 424-431, 2008.

[104] J. M. Schwarz, P. Linfoot, D. Dare, and K. Aghajanian, "Hepatic de novo lipogenesis in normoinsulinemic and hyperinsulinemic subjects consuming high-fat, low-carbohydrate and low-fat, high-carbohydrate isoenergetic diets," American Journal of Clinical Nutrition, vol. 77, no. 1, pp. 43-50, 2003.

[105] J. D. Horton, J. L. Goldstein, and M. S. Brown, "SREBPs: activators of the complete program of cholesterol and fatty acid synthesis in the liver," Journal of Clinical Investigation, vol. 109, no. 9, pp. 1125-1131, 2002.

[106] S. Polvani, M. Tarocchi, and A. Galli, "PPAR $y$ and oxidative stress: $\operatorname{con}(\beta)$ catenating NRF2 and FOXO," PPAR Research, vol. 2012, Article ID 641087, 15 pages, 2012.

[107] O. Cheung and A. J. Sanyal, "Abnormalities of lipid metabolism in nonalcoholic fatty liver disease," Seminars in Liver Disease, vol. 28, no. 4, pp. 351-359, 2008. 
[108] Z. Zheng, C. Zhang, and K. Zhang, "Role of unfolded protein response in lipogenesis," World Journal of Gastroenterology, vol. 2, no. 6, pp. 203-207, 2010.

[109] G. S. Hotamisligil, "Endoplasmic reticulum stress and the inflammatory basis of metabolic disease," Cell, vol. 140, no. 6, pp. 900-917, 2010.

[110] M. P. Mollica, L. Lionetti, R. Putti, G. Cavaliere, M. Gaita, and A. Barletta, "From chronic overfeeding to hepatic injury: role of endoplasmic reticulum stress and inflammation," Nutrition, Metabolism and Cardiovascular Diseases, vol. 21, no. 3, pp. 222-230, 2011.

[111] G. Boden, X. Duan, C. Homko et al., "Increase in endoplasmic reticulum stress-related proteins and genes in adipose tissue of obese, insulin-resistant individuals," Diabetes, vol. 57, no. 9, pp. 2438-2444, 2008.

[112] A. Chakrabarti, A. W. Chen, and J. D. Varner, "A review of the mammalian unfolded protein response," Biotechnology and Bioengineering, vol. 108, no. 12, pp. 2777-2793, 2011.

[113] M. J. Gething, "Role and regulation of the ER chaperone BiP," Seminars in Cell and Developmental Biology, vol. 10, no. 5, pp. 465-472, 1999.

[114] H. Malhi and R. J. Kaufman, "Endoplasmic reticulum stress in liver disease," Journal of Hepatology, vol. 54, no. 4, pp. 795809, 2011.

[115] A. Z. Reznick and L. Packer, "Oxidative damage to proteins: spectrophotometric method for carbonyl assay," Methods in Enzymology, vol. 233, pp. 357-363, 1994.

[116] R. T. Dean, S. Gieseg, and M. J. Davies, "Reactive species and their accumulation on radical-damaged proteins," Trends in Biochemical Sciences, vol. 18, no. 11, pp. 437-441, 1993.

[117] E. R. Stadtman, "Metal ion-catalyzed oxidation of proteins: biochemical mechanism and biological consequences," Free Radical Biology and Medicine, vol. 9, no. 4, pp. 315-325, 1990.

[118] M. F. Gregor, L. Yang, E. Fabbrini et al., "Endoplasmic reticulum stress is reduced in tissues of obese subjects after weight loss," Diabetes, vol. 58, no. 3, pp. 693-700, 2009.

[119] P. Puri, F. Mirshahi, O. Cheung et al., "Activation and dysregulation of the unfolded protein response in nonalcoholic fatty liver disease," Gastroenterology, vol. 134, no. 2, pp. 568576, 2008.

[120] N. K. Sharma, S. K. Das, A. K. Mondal et al., "Endoplasmic reticulum stress markers are associated with obesity in nondiabetic subjects," Journal of Clinical Endocrinology and Metabolism, vol. 93, no. 11, pp. 4532-4541, 2008.

[121] C. Appenzeller-Herzog, "Glutathione- and non-glutathionebased oxidant control in the endoplasmic reticulum," Journal of Cell Science, vol. 124, part 6, pp. 847-855, 2011.

[122] I. Kim, W. Xu, and J. C. Reed, "Cell death and endoplasmic reticulum stress: disease relevance and therapeutic opportunities," Nature Reviews Drug Discovery, vol. 7, no. 12, pp. 1013-1030, 2008.

[123] M. Orellana, R. Rodrigo, N. Varela et al., "Relationship between in vivo chlorzoxazone hydroxylation, hepatic cytochrome P450 2E1 content and liver injury in obese nonalcoholic fatty liver disease patients," Hepatology Research, vol. 34, no. 1, pp. 57-63, 2006.

[124] S. Seki, T. Kitada, and H. Sakaguchi, "Clinicopathological significance of oxidative cellular damage in non-alcoholic fatty liver diseases," Hepatology Research, vol. 33, no. 2, pp. 132-134, 2005.

[125] N. Chalasani, M. A. Deeg, and D. W. Crabb, "Systemic levels of lipid peroxidation and its metabolic and dietary correlates in patients with nonalcoholic steatohepatitis,"
American Journal of Gastroenterology, vol. 99, no. 8, pp. 14971502, 2004.

[126] Z. Yesilova, H. Yaman, C. Oktenli et al., "Systemic markers of lipid peroxidation and antioxidants in patients with nonalcoholic fatty liver disease," American Journal of Gastroenterology, vol. 100, no. 4, pp. 850-855, 2005.

[127] M. Konishi, M. Iwasa, J. Araki et al., "Increased lipid peroxidation in patients with non-alcoholic fatty liver disease and chronic hepatitis $\mathrm{C}$ as measured by the plasma level of 8isoprostane," Journal of Gastroenterology and Hepatology, vol. 21, no. 12, pp. 1821-1825, 2006.

[128] G. Robertson, I. Leclercq, and G. C. Farrell, "Nonalcoholic Steatosis and Steatohepatitis. II. Cytochrome P-450 enzymes and oxidative stress," American Journal of Physiology, vol. 281, no. 5, pp. G1135-G1139, 2001.

[129] M. Pérez-Carreras, P. Del Hoyo, M. A. Martín et al., "Defective hepatic mitochondrial respiratory chain in patients with nonalcoholic steatohepatitis," Hepatology, vol. 38, no. 4, pp. 999-1007, 2003.

[130] H. Cortez-Pinto, J. Chatham, V. P. Chacko, C. Arnold, A. Rashid, and A. M. Diehl, "Alterations in liver ATP homeostasis in human nonalcoholic steatohepatitis: a pilot study," Journal of the American Medical Association, vol. 282, no. 17, pp. 1659-1664, 1999.

[131] L. A. Videla, G. Tapia, R. Rodrigo et al., "Liver NF- $\kappa$ B and AP-1 DNA binding in obese patients," Obesity, vol. 17, no. 5, pp. 973-979, 2009.

[132] P. S. Ribeiro, H. Cortez-Pinto, S. Solá et al., "Hepatocyte apoptosis, expression of death receptors, and activation of NF- $\kappa$ B in the liver of nonalcoholic and alcoholic steatohepatitis patients," American Journal of Gastroenterology, vol. 99, no. 9, pp. 1708-1717, 2004.

[133] G. Gloire, S. Legrand-Poels, and J. Piette, "NF- $\kappa$ B activation by reactive oxygen species: fifteen years later," Biochemical Pharmacology, vol. 72, no. 11, pp. 1493-1505, 2006.

[134] W. E. Naugler and M. Karin, "NF- $\kappa$ B and cancer-identifying targets and mechanisms," Current Opinion in Genetics and Development, vol. 18, no. 1, pp. 19-26, 2008.

[135] H. Kamata, S. I. Honda, S. Maeda, L. Chang, H. Hirata, and M. Karin, "Reactive oxygen species promote TNF $\alpha$-induced death and sustained JNK activation by inhibiting MAP kinase phosphatases," Cell, vol. 120, no. 5, pp. 649-661, 2005.

[136] L. A. Videla, "Liver NF- $\kappa$ B and AP- 1 activation and PPAR- $\alpha$ expression are negatively correlated in obese patients: proinflammatory implications," Clinical Nutrition, vol. 29, no. 5, pp. 687-688, 2010.

[137] A. J. Wigg, I. C. Roberts-Thomson, R. B. Dymock, P. J. McCarthy, R. H. Grose, and A. G. Cummins, "The role of small intestinal bacterial overgrowth, intestinal permeability, endotoxaemia, and tumour necrosis factor $\alpha$ in the pathogenesis of non-alcoholic steatohepatitis," Gut, vol. 48, no. 2, pp. 206-211, 2001.

[138] J. Crespo, A. Cayoen, P. Fernendez-Gil et al., "Gene expression of tumor necrosis factor $\alpha$ and TNF-receptors, p55 and p75, in nonalcoholic steatohepatitis patients," Hepatology, vol. 34, no. 6, pp. 1158-1163, 2001.

[139] J. M. Hui, A. Hodge, G. C. Farrell, J. G. Kench, A. Kriketos, and J. George, "Beyond insulin resistance in NASH: TNF- $\alpha$ or adiponectin?" Hepatology, vol. 40, no. 1, pp. 46-54, 2004.

[140] A. Guerra Ruiz, F. Casafont, J. Crespo et al., "Lipopolysaccharide-binding protein plasma levels and liver TNFalpha gene expression in obese patients: evidence for 
the potential role of endotoxin in the pathogenesis of nonalcoholic steatohepatitis," Obesity Surgery, vol. 17, no. 10, pp. 1374-1380, 2007.

[141] R. F. Schwabe, E. Seki, and D. A. Brenner, "Toll-like receptor signaling in the liver," Gastroenterology, vol. 130, no. 6, pp. 1886-1900, 2006.

[142] M. S. Hayden and S. Ghosh, "Signaling to NF- $\kappa$ B," Genes and Development, vol. 18, no. 18, pp. 2195-2224, 2004.

[143] C. L. Gentile, M. A. Frye, and M. J. Pagliassotti, "Fatty acids and the endoplasmic reticulum in nonalcoholic fatty liver disease," BioFactors, vol. 37, no. 1, pp. 8-16, 2011.

[144] M. Capanni, F. Calella, M. R. Biagini et al., "Prolonged n-3 polyunsaturated fatty acid supplementation ameliorates hepatic steatosis in patients with non-alcoholic fatty liver disease: a pilot study," Alimentary Pharmacology and Therapeutics, vol. 23, no. 8, pp. 1143-1151, 2006.

[145] L. Spadaro, O. Magliocco, D. Spampinato et al., "Effects of $\mathrm{n}-3$ polyunsaturated fatty acids in subjects with nonalcoholic fatty liver disease," Digestive and Liver Disease, vol. 40, no. 3, pp. 194-199, 2008.

[146] F. S. Zhu, S. Liu, X. M. Chen, Z. G. Huang, and D. W. Zhang, "Effects of n-3 polyunsaturated fatty acids from seal oils on nonalcoholic fatty liver disease associated with hyperlipidemia," World Journal of Gastroenterology, vol. 14, no. 41, pp. 6395-6400, 2008.

[147] A. Hatzitolios, C. Savopoulos, G. Lazaraki et al., "Efficacy of omega-3 fatty acids, atorvastatin and orlistat in nonalcoholic fatty liver disease with dyslipidemia," Indian Journal of Gastroenterology, vol. 23, no. 4, pp. 131-134, 2004.

[148] N. Tanaka, K. Sano, A. Horiuchi, E. Tanaka, K. Kiyosawa, and T. Aoyama, "Highly purified eicosapentaenoic acid treatment improves nonalcoholic steatohepatitis," Journal of Clinical Gastroenterology, vol. 42, no. 4, pp. 413-418, 2008.

[149] H. M. Parker, N. A. Johnson, C. A. Burdon, J. S. Cohn, H. T. O'Connor, and J. George, "Omega-3 supplementation and non-alcoholic fatty liver disease: a systematic and metaanalysis," Journal of Hepatology, vol. 56, no. 4, pp. 944-951, 2012.

[150] D. B. Jump, "N-3 polyunsaturated fatty acid regulation of hepatic gene transcription," Current Opinion in Lipidology, vol. 19, no. 3, pp. 242-247, 2008.

[151] B. De Roos, Y. Mavrommatis, and I. A. Brouwer, "Long-chain n-3 polyunsaturated fatty acids: new insights into mechanisms relating to inflammation and coronary heart disease," British Journal of Pharmacology, vol. 158, no. 2, pp. 413-428, 2009.

[152] H. Shapiro, M. Tehilla, J. Attal-Singer, R. Bruck, R. Luzzatti, and P. Singer, "The therapeutic potential of long-chain omega-3 fatty acids in nonalcoholic fatty liver disease," Clinical Nutrition, vol. 30, no. 1, pp. 6-19, 2011. 


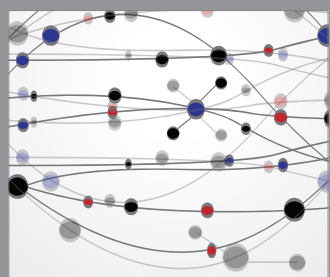

The Scientific World Journal
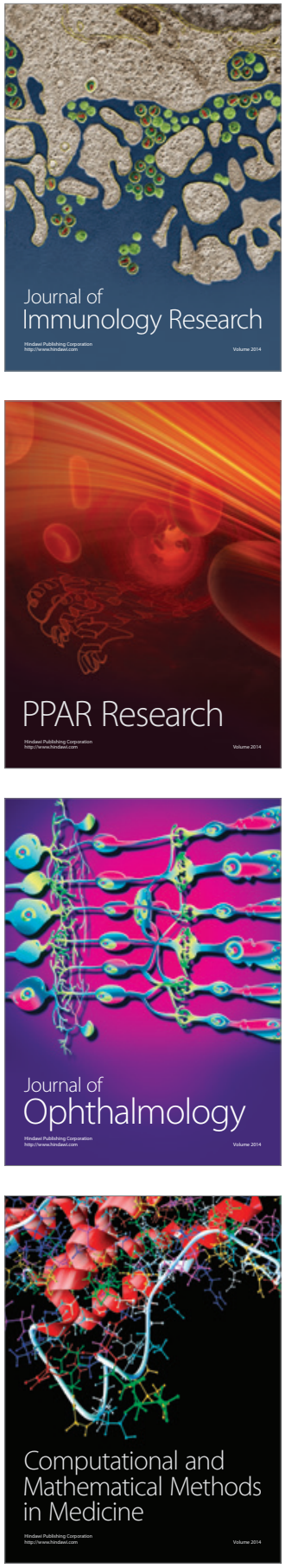

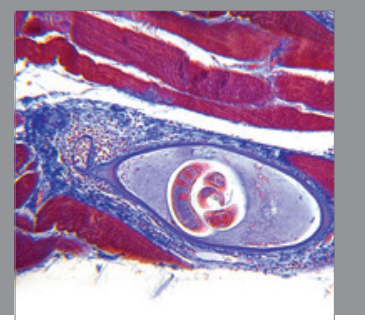

Gastroenterology

Research and Practice
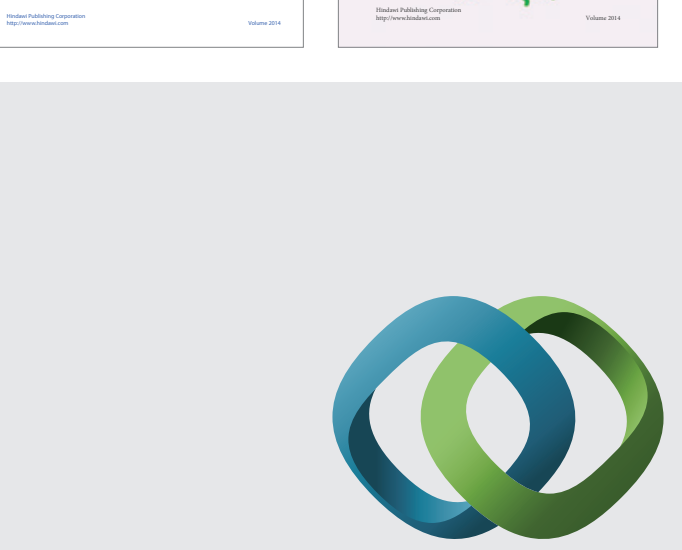

\section{Hindawi}

Submit your manuscripts at

http://www.hindawi.com
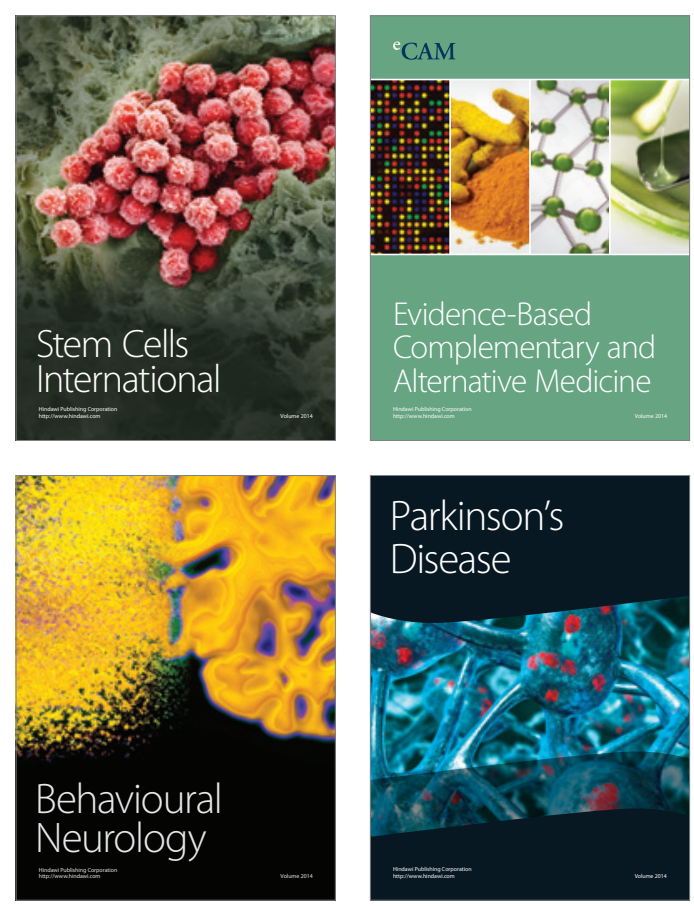

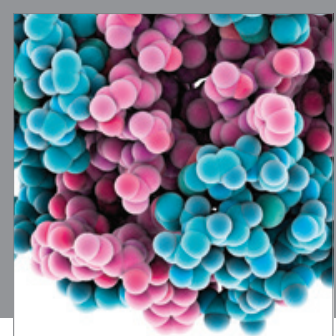

Journal of
Diabetes Research

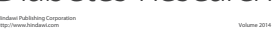

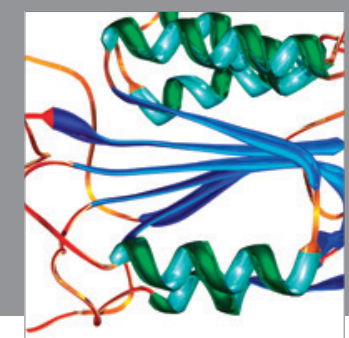

Disease Markers
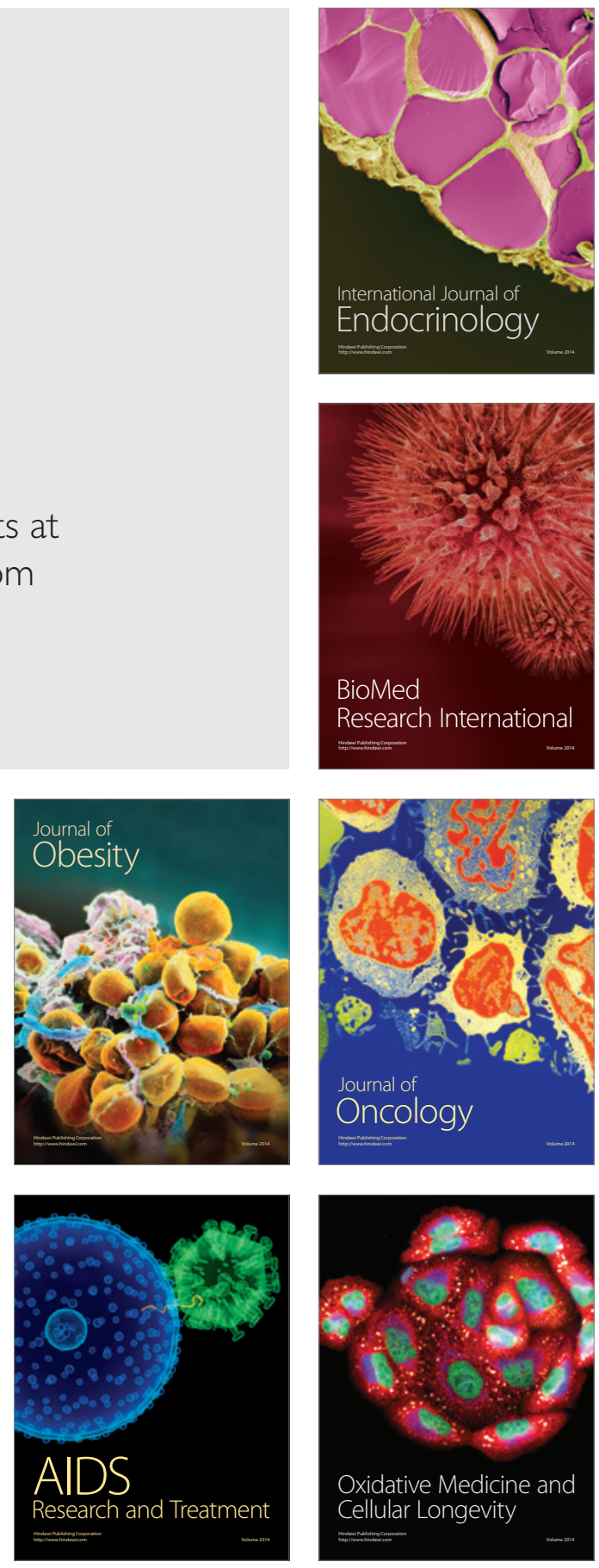